\title{
Spray Formation from Spark-Eroded and Laser-Drilled Injectors for DISI Engines with Gasoline and Alcohol Fuels
}

\author{
Markus Behringer and Pavlos Aleiferis \\ University College London
}

\author{
Dave OudeNijeweme and Paul Freeland \\ MAHLE Powertrain Ltd.
}

Copyright @ 2014 SAE International

\begin{abstract}
One of the latest advancements in injector technology is laser drilling of the nozzle holes. In this context, the spray formation and atomisation characteristics of gasoline, ethanol and 1butanol were investigated for a 7-hole spark eroded (SE) injector and its 'direct replacement' Laser-drilled (LD) injector using optical techniques. In the first step of the optical investigation, high-speed spray imaging was performed in a quiescent injection chamber with global illumination using diffused Laser light. The images were statistically analyzed to obtain spray penetration, spray tip velocity and spray 'cone' angles. Furthermore, droplet sizing was undertaken using Phase Doppler Anemometry (PDA). A single spray plume was isolated for this analysis and measurements were obtained across the plume at a fixed distance from the nozzle exit. The droplet measurements were grouped into bins and maps were created showing droplet sizes and velocities against time and position during and post injection. All tests were performed at 120 bar fuel pressure, two injection chamber 'back' pressures ( 0.5 bar and 1 bar) and two injector temperatures $\left(20^{\circ} \mathrm{C}\right.$ and $80^{\circ} \mathrm{C}$ ), to examine effects relevant to typical engine operating conditions with early intake stroke injection strategies, including fuel flash boiling.
\end{abstract}

\section{Introduction}

\section{Background}

The design of new direct injection systems for spark-ignition engines is very important for improved atomisation and mixture formation with different fuels, as well as low exhaust emissions, including particulates that are central to EU6 regulations. It is preferable to meet the proposed targets by means of engine internal measures rather than separate treatment in the exhaust system that can be associated with a CO2 penalty. Latest injector manufacturing methods by Laserdrilling have shown some promising results. Specifically, Whitaker et al. [1] showed a significant reduction in particulates using a Laser-drilled in comparison to a spark-eroded multi hole injector; however, in their study the exact nozzle design was not specified. As particulates are generally attributed to poor atomization, wall wetting and incomplete air-fuel mixing, it is important to understand the differences in fuel spay formation between spark-eroded and Laser-drilled injectors.

Page 1 of 19
The challenge is further complicated by the predicted fuel stock that may contain significant amounts of biofuels. To overcome ethical issues, it is also important to ensure that any new fuels will not compete with food chains, hence alternative ways of their large scale production such as, amongst others, e.g. cellulosic or hemicellulosic feedstock are being established. Ethanol is to date still one of the preferred renewable additives or substitutes to gasoline; amongst its favorable properties is the fuel octane number enhancing capability. Butanol is also believed to be suitable to play a strong role. The use of butanol may not require major modifications to the current infrastructure and is also more compatible with some materials used in injection system technologies. Butanol is also less hygroscopic, has a lower vapor pressure and its heating value is higher than ethanol's. Butanol production processes are already established and have the potential to be widened to have similar capabilities to ethanol production [2].

\section{Present Contribution}

The manufacturing process of Laser drilling generally allows for the implementation of complex geometrical aids to promote or suppress turbulence and cavitation as needed [3] but to the best of the authors' knowledge, there are no other major publications that have compared the atomization characteristics from spark-eroded and Laser-drilled injectors. In this context, the work in this paper characterized the mechanism of spray formation from two injectors, one sparkeroded and its 'like-for-like' replacement Laser-drilled injector in order to understand associated effects. The main objectives of the work are summarized below:

- Visual analysis of the sprays produced by the two injectors using high-speed imaging.

- Quantification of the sprays' geometrical features, including penetration, as well as overall outer envelope 'cone' angles at $5 \mathrm{~mm}$ and $25 \mathrm{~mm}$ from the nozzle.

- Droplet sizing by Phase Doppler Anemometry (PDA).

- Study of the effect of fuel type, primarily gasoline, ethanol and butanol, with both injectors. Some measurements and analysis was also performed with iso-octane, as the latter is a common fuel used for research purposes and can be useful in the research community for direct comparisons with previous work on injectors. 


\section{INJECTORS AND FUELS}

\section{Fuels}

The fuels used to compare the two injectors were selected to be significantly different in terms of fuel properties. Regular gasoline (RON95) with its wide range of low to high volatility fractions was used alongside the single components ethanol and 1-butanol (also denoted E100 and B100 respectively). Some measurements were also conducted with iso-octane which is a popular single-component research surrogate for gasoline. Differences in viscosity, surface tension, latent heat, boiling point and vapor pressure are all important in terms of spray formation; a summary of the fuel properties is given in Table 1. Figures 1 and 2 show the distillation curve and vapor pressure against fuel temperature. The refractive index of the fuels was also measured (from $20-70^{\circ} \mathrm{C}$ and extrapolated; at $514 \mathrm{~nm}$ ) as shown in Figure 3.

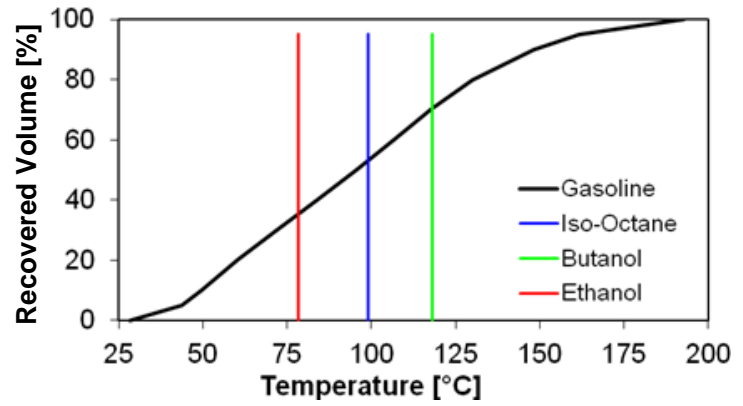

Figure 1. Distillation curve of gasoline (measured) and boiling points of single components [12].

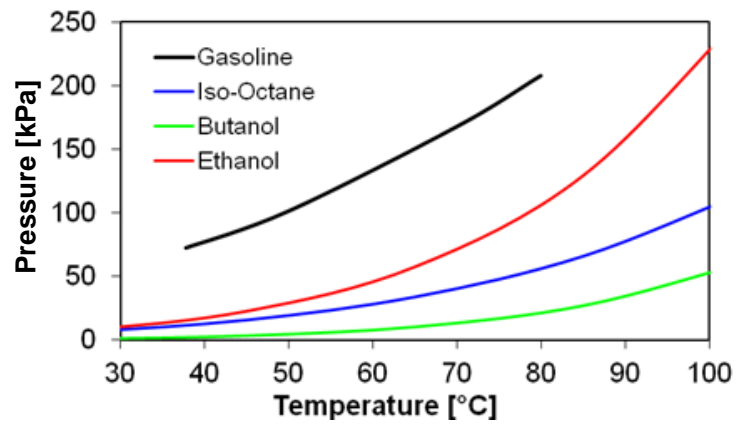

Figure 2. Vapour pressure against fuel temperature of gasoline (measured) and boiling points of single components [12].

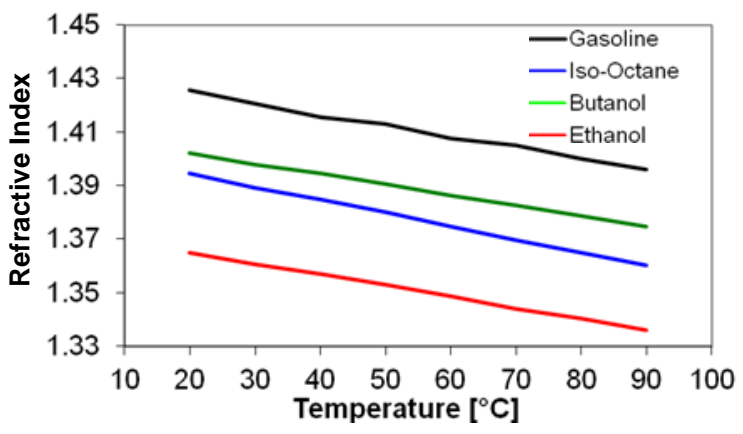

Figure 3. Refractive index (measured).
Table 1. Basic fuel properties.

\begin{tabular}{|c|c|c|c|c|}
\hline & Ethanol & 1-Butanol & Gasoline & Iso-Oct. \\
\hline Chemical formula & $\mathrm{C} 2 \mathrm{H} 5 \mathrm{OH}$ & $\mathrm{C} 4 \mathrm{H} 9 \mathrm{OH}$ & $\sim \mathrm{C} 4-\mathrm{C} 12$ & $\mathrm{C} 8 \mathrm{H} 18$ \\
\hline Molar mass $[\mathrm{g} / \mathrm{mol}]^{a}$ & 46.07 & 74.12 & $100-105$ & 114.3 \\
\hline Density $20^{\circ} \mathrm{C}\left[\mathrm{g} / \mathrm{cm}^{3}\right]$ & 0.79 & 0.81 & 0.72 & 0.69 \\
\hline Density $80^{\circ} \mathrm{C}\left[\mathrm{g} / \mathrm{cm}^{3}\right]$ & 0.73 & 0.76 & 0.66 & 0.64 \\
\hline Solub. in water $\left(20^{\circ} \mathrm{C}\right)[\mathrm{g} / \mathrm{l}]$ & miscible & 79 & partially & not \\
\hline Boiling point $\left[{ }^{\circ} \mathrm{C}\right]$ & 78.3 & 118 & 30 to 210 & 99 \\
\hline Flash point $\left[{ }^{\circ} \mathrm{C}\right]$ & 12 & 30 & -43 & -12 \\
\hline Ignition temp. $\left[{ }^{\circ} \mathrm{C}\right]$ & 425 & 340 & $>350$ & 410 \\
\hline DVPE at $20^{\circ} \mathrm{C}[\mathrm{kPa}]$ & $6.4^{d}$ & $0.8^{d}$ & $35^{i}$ & $5.7^{d}$ \\
\hline DVPE at $37.8^{\circ} \mathrm{C}(\sim \mathrm{RVP})[\mathrm{kPa}]$ & $16.1^{d}$ & $2.2^{d}$ & $72.4^{i}$ & $11.8^{d}$ \\
\hline DVPE at $80^{\circ} \mathrm{C}[\mathrm{kPa}]$ & $100^{d}$ & $16.4^{d}$ & $208^{i}$ & $50^{d}$ \\
\hline Bubble Point ( 0.5 bar) $\left[{ }^{\circ} \mathrm{C}\right]$ & 62.6 & 108.8 & 29.8 & 80 \\
\hline Kin. viscosity $\left(23^{\circ} \mathrm{C}\right)[\mathrm{cSt}]$ & $1.33^{i}$ & $3.22^{i}$ & $0.47^{i}$ & $0.62^{i}$ \\
\hline Kin. viscosity $\left(80^{\circ} \mathrm{C}\right)[\mathrm{cSt}]$ & $0.60^{i}$ & $0.99^{i}$ & $0.25^{j}$ & $0.40^{i}$ \\
\hline Surface tension $\left(23^{\circ} \mathrm{C}\right)[\mathrm{mN} / \mathrm{m}]$ & $23.01^{i}$ & $25.50^{i}$ & $21.80^{i}$ & $18.78^{i}$ \\
\hline Surface tension $\left(80^{\circ} \mathrm{C}\right)[\mathrm{mN} / \mathrm{m}]$ & $16.4^{d}$ & $19.3^{d}$ & - & $13.6^{d}$ \\
\hline Expl. limit (upper) [Vol\%] & 15 & 11.3 & 7.6 & 6 \\
\hline Expl. limit (lower) [Vol\%] & 3.5 & 1.4 & 1.4 & 1 \\
\hline Latent heat (at $T_{\text {boil }}[\mathrm{kJ} / \mathrm{kg}]$ ) & $855^{d}$ & $584^{d}$ & 364 & $272^{d}$ \\
\hline Latent heat $\left(25^{\circ} \mathrm{C}\right)[\mathrm{kJ} / \mathrm{kg}]$ & $874^{d}$ & $669^{d}$ & $380-500$ & $300^{d}$ \\
\hline Stoichiometric AFR & 9 & 11.1 & 14.6 & 15.1 \\
\hline Heating value $[\mathrm{MJ} / \mathrm{kg}],[\mathrm{MJ} / \mathrm{l}]$ & $26.9,21.3^{d}$ & $33.9,27.5^{d}$ & $42.7,32^{c}$ & $44.6,30.8^{d}$ \\
\hline Specific heat cp $\left(25^{\circ} \mathrm{C}\right)[\mathrm{kJ} / \mathrm{kgK}]$ & $2.46^{d}$ & $2.30^{d}$ & $2.22^{c}$ & $2.09^{d}$ \\
\hline Specific energy [MJ/kg air] & 2.99 & 3.01 & 2.92 & 2.94 \\
\hline \multicolumn{4}{|l|}{ laminar burning velocity $[\mathrm{m} / \mathrm{s}]$} & $25,17^{e}$ \\
\hline RON & $129^{f}$ & $96^{f}$ & 95 & 100 \\
\hline $\mathrm{H} / \mathrm{C}, \mathrm{O} / \mathrm{C}$ & $3,0.5$ & $2.5,0.25$ & $1.92,0$ & $2.25,0$ \\
\hline $\begin{array}{l}\text { If not specified, data taken fror } \\
\text { Calculated [10]. } \\
\text { Calculated [11]. } \\
\text { Calculated [12]. } \\
\text { Taken from [13, 14]. } \\
\text { Taken from [15]. } \\
\text { Measured values. } \\
\text { Estimated values based on me }\end{array}$ & n product da & ta sheets. & & \\
\hline
\end{tabular}

\section{Injector Nozzles}

Two 7-hole solenoid injectors designed for side mounting in the combustion chambers of a 4 cylinder 2.0 I engine were the focus of the investigation. The first injector had a standard spark-eroded nozzle (MH7-SE) while the second was its 'direct replacement' manufactured using Laser drilling (MH7-LD). Despite being 'like-for-like direct replacements', first visual inspection under a microscope revealed similar stepped hole pattern but different hole diameters, as shown in Figure 4. specifically, the outer hole diameter of the SE injector was measured $0.39 \mathrm{~mm}$ and the inner step $0.21 \mathrm{~mm}$. The respective dimensions of the LD injector were 0.43 and 0.24 $\mathrm{mm}$.

Considering that the manufacturing process of Laser drilling generally allows for the implementation of complex geometrical aids to promote or suppress turbulence and cavitation [3], silicone castings were used to obtain more detailed information about the inner nozzle shape and surface quality according to [4] and [5]. The obtained castings are shown schematically in Figure 5.

Page 2 of 19 

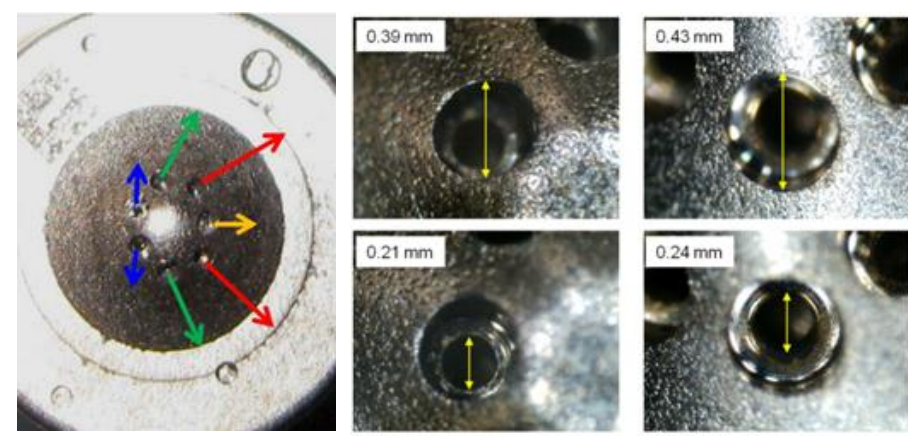

Figure 4. Injector hole layout (left) and stepped hole outer and inner dimensions (middle SE, right LD injector).

Spark Eroded Nozzle
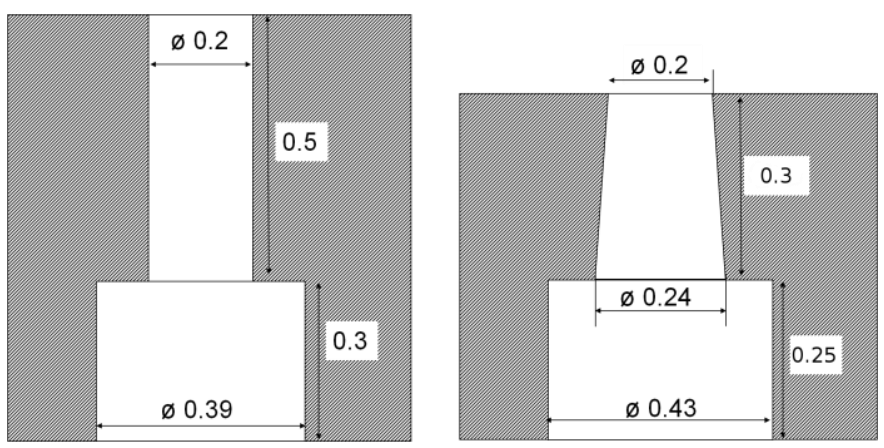

Figure 5. Sketch of SE( left) and LD (right); nozzle hole design; nozzle outlet is at the bottom, inlet at the top.

The spark eroded injector featured an inner, spark-eroded, cylindrical bore with a diameter of $0.2 \mathrm{~mm}$ and a length of $\sim 0.5$ $\mathrm{mm}$, before opening up into a drilled hole with a diameter of $0.39 \mathrm{~mm}$ and a depth of $\sim 0.3 \mathrm{~mm}$. This diameter step is commonly associated with benefits regarding reduction of deposit formation. This injector-hole design is believed to feature two regions of flow separation. The first one is located at the entrance of the inner bore, where a vena contracta is formed that reduces the effective diameter (generally by a factor of $\sim 0.6$ ). A low pressure recirculation area is hence formed at the inlet edge, promoting cavitation. When exiting the inner hole and the flow enters the larger outer hole, a similar phenomenon is to be expected but this now leads to the onset of atomisation. In contrast, for the Laser-drilled injector, it was found that the outer hole remained conventionally drilled and it was cylindrical with a diameter of $\sim 0.43 \mathrm{~mm}$ and $\sim 0.3$ $\mathrm{mm}$ length, while the inner, Laser drilled, hole was of a conical shape with a start diameter of $0.2 \mathrm{~mm}$, opening up to $0.24 \mathrm{~mm}$ over a distance of $0.3 \mathrm{~mm}$. Such design differences further highlighted the necessity for behavioural analysis for engine developers and calibrators with a view of incorporating suitable adjustments for optimised engine performance when injector types are replaced.

For example, the increased surface smoothness of the laser drilling, that was distinctly visible in electron microscope imaging, can reduce the friction factor of the nozzle, in addition to reduced losses by the shorter conically shaped nozzle. Furthermore, the conical hole creates a more acute angle at the entrance (by $\sim 4^{\circ}$ ) and the incoming liquid will experience a stronger flow separation in the zone past the entry corner. The separation region may not only be wider but can also be maintained for longer downstream, or never really reattach due to the ever increasing hole diameter. This is believed to induce and maintain cavitation more readily. Regarding turbulence, the effect of the nozzle cone is not necessarily clear in practice, especially over a range of operating conditions. As the entry into the flow channel is of identical size between the two injectors, the respective Reynolds $(R e)$ and Ohnesorge (Oh) numbers can easily be estimated by using 'average' flow velocities derived from mass flow measurements. However, the vena contracta can reduce the effective hole diameter, hence flow velocities and associated Re numbers can be much larger than such basic estimated values. The conical shape of the LD nozzle can also lead to flow relaxation with lower $R e$ number as the hole area increases, but the short length and flow momentum may not allow for immediate flow adaption as the residence time in the nozzle is very short; therefore, the difference in inferred turbulence may not be as large as expected when using the outer hole diameter for Re number estimations.

The maximum initial droplet sizes and associated Weber numbers when the liquid leaves the nozzle are often based on the nozzle-hole dimensions (or at least of the same order). However, the actual hole diameter influence may not play a significant role in the presence of strong cavitation when the process of exiting is accompanied by violent disruption. In contrast, in absence of cavitation, fuels with low vapour pressure, high viscosity and therefore low $\operatorname{Re}$ (e.g. cold butanol as the extreme of the current experiment) could be affected by the larger opening of the LD injector compared to the SE nozzle; hence larger initial droplet sizes could follow. In fact, as will be shown later, the LD nozzle did actually produce larger droplets for ethanol and butanol, but not for the 'more cavitating' gasoline or E25.

\section{Mass Flow Analysis}

Experiments were first carried out to establish the injectors' flow rates with 120 bar injection pressure. Injected fuel quantities were measured for gasoline, iso-octane, ethanol and butanol fuels. The injected fuel was collected over 200 injection events at an injector body temperature of $20^{\circ} \mathrm{C}$ and $80^{\circ} \mathrm{C}$ and 1 bar ambient air pressure (the injector was heated using a sleeve heater around the injector's mounting block). Figure 5 shows the injected fuel mass for gasoline using a range of injection durations up to $1.5 \mathrm{~ms}\left(20^{\circ} \mathrm{C}, 1 \mathrm{bar}\right)$. Both injectors showed no injected fuel with injection trigger pulse durations lower than $0.25 \mathrm{~ms}$. With durations longer than this, the flow rate of the Laser-drilled injector was always larger than the spark-eroded injector's, typically in the region of $10 \%$. This is much less than what one would expect from continuity calculations on the basis of the differences in nozzle hole diameters between the two injectors and can be attributed to further differences in the inner shape of the hole geometry that could influence in-nozzle two-phase flow effects.

Figure 5 shows the injected fuel mass for gasoline using a range of injection durations up to $1.5 \mathrm{~ms}\left(20^{\circ} \mathrm{C}, 1 \mathrm{bar}\right)$. Both injectors showed no injected fuel with injection trigger pulse durations lower than $0.25 \mathrm{~ms}$. With durations longer than this, the flow rate of the Laser-drilled injector was always larger than the spark-eroded injector's, typically in the region of $10 \%$. This 
is much less than what one would expect from continuity calculations on the basis of the differences in nozzle hole diameters between the two injectors and can be attributed to further differences in the inner shape of the hole geometry that could influence in-nozzle two-phase flow effects.

Figures 6 and 7 show the mass flow for all fuels at $20^{\circ} \mathrm{C}$ and $80^{\circ} \mathrm{C}$ injector conditions for a pulse duration of $1.26 \mathrm{~ms}$. The latter represented the injection pulse duration to obtain close to stoichiometric conditions overall at an operating point of 0.5 bar intake plenum pressure, 1500 RPM, inside the cylinder of an optical research engine of 0.5 I capacity.

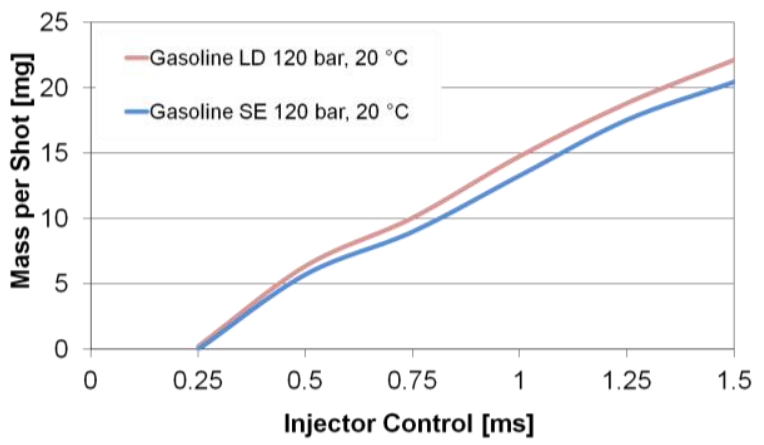

Figure 5. Injection quantity vs. pulse time at $20^{\circ} \mathrm{C}$ injector temperature, 120 bar fuel pressure, 1 bar back pressure.

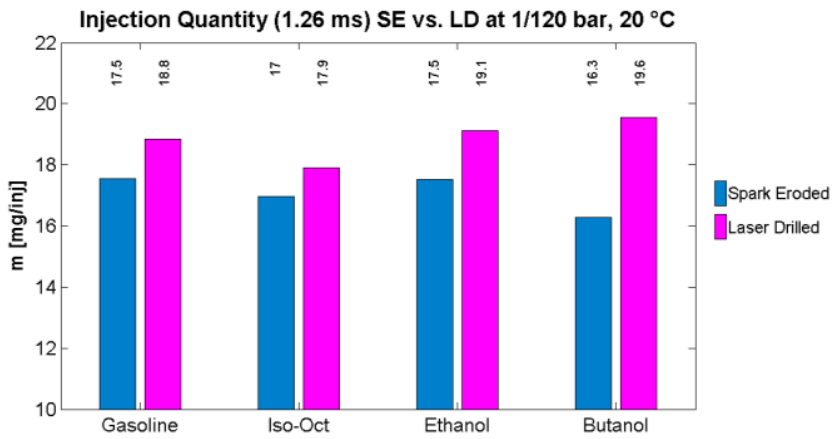

Figure 6. Injection quantity at $20^{\circ} \mathrm{C}$ injector temperature, 120 bar fuel pressure, 1 bar back pressure (1.26 ms pulse).

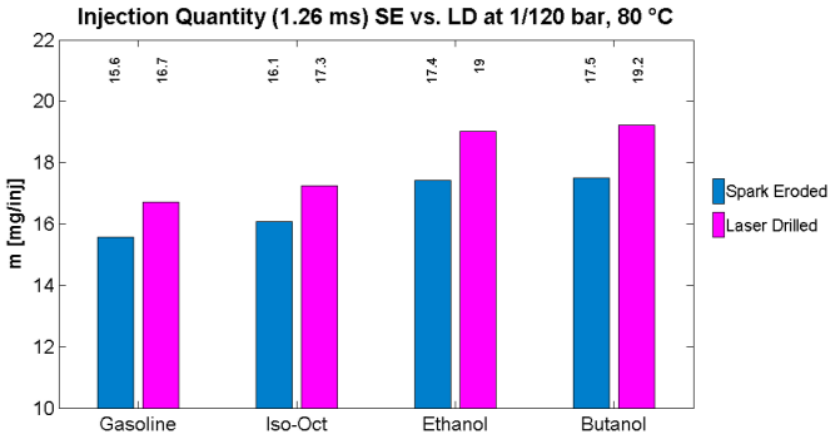

Figure 7. Injection quantity at $80^{\circ} \mathrm{C}$ injector temperature, 120 bar fuel pressure, 1 bar back pressure (1.26 ms pulse)

Those values were used to derive equivalent fuel flow velocities and then Reynolds and Ohnesorge numbers using fuel properties, as shown in Figure 8. This analysis showed that the breakup was within the atomisation regime for all fuels with the exception of cold butanol, where the SE injector was on the border to the 2 nd wind induced regime (regimes according to Reitz and Bracco [6]). Higher temperatures increased the flow for butanol inside the SE injector, while all other fuels showed a decrease in injection quantity. The decrease was strongest for gasoline. Cavitation and flash boiling effects are believed to be the main underlying cause for the reduced flow rates, as the reduced fuel viscosity on its own should have increased the flow at higher temperature. The latter may be dominant though for butanol whose flow rate increased.

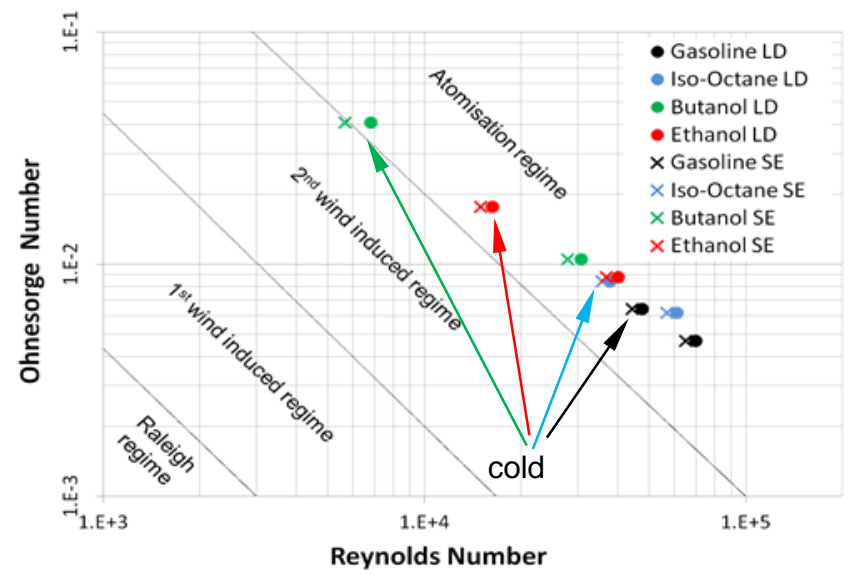

Figure 8. Ohnesorge diagram as from mass flow analysis.

\section{Setup and Methodology}

\section{Spray Imaging Setup}

The inner diameter of the quiescent injection chamber, shown in full setup in Figure 9, was $180 \mathrm{~mm}$ and the height $300 \mathrm{~mm}$. The top cover, where the injectors were placed, was protruding into the inside of the chamber giving a final chamber volume of $\sim 7$ liters. Four optically polished UV grade fused silica windows with a diameter of $95 \mathrm{~mm}$ and a thickness of $32 \mathrm{~mm}$ allowed optical access. For spray imaging, a Photron APX-RS highspeed CMOS camera was used to take 60 images per injection event at a set to a frame rate of $9 \mathrm{kHz}$ (this corresponded to $1^{\circ}$ crank angle resolution for an engine operating at 1500 RPM). The camera's internal memory allowed acquisition of 113 injection events at $640 \times 480$ pixels. The injection duration was fixed to $1.26 \mathrm{~ms}$.

The spray was illuminated at a $90^{\circ}$ angle by pulsed light of a 527 nm Pegasus-PIV New Wave Nd:YLF high speed Laser, allowing for a light exposure of the camera chip of $<180 \mathrm{~ns}$. The Laser's energy stability of $<1 \%$ promised low shot-to-shot variation, critical for the image analysis. The high repetition rate diode pumped Laser was capable providing $10 \mathrm{~mJ}$ per cavity. It was synchronized with the high speed camera and the injector driver using a AVL 427 timing unit. A Nikon Nikkor $28 \mathrm{~mm}$ macro lens was used for the experiments. The resulting resolution was $122 \mu \mathrm{m}$ per pixel with the camera focus set to the chamber centre at an object distance of $230 \mathrm{~mm}$. The $\mathrm{f}-$ stop was $f / 5.6$ resulting in a depth of field of $\sim 14 \mathrm{~mm}$. The 
nominally $1.5 \mathrm{~mm}$ Laser beam was diffused using a lens of short focal length and frosted glass for evenly distributed illumination of the spray to obtain consistent Mie scattering. Speckles created by the Laser were greatly reduced by the use of multiple diffusers.

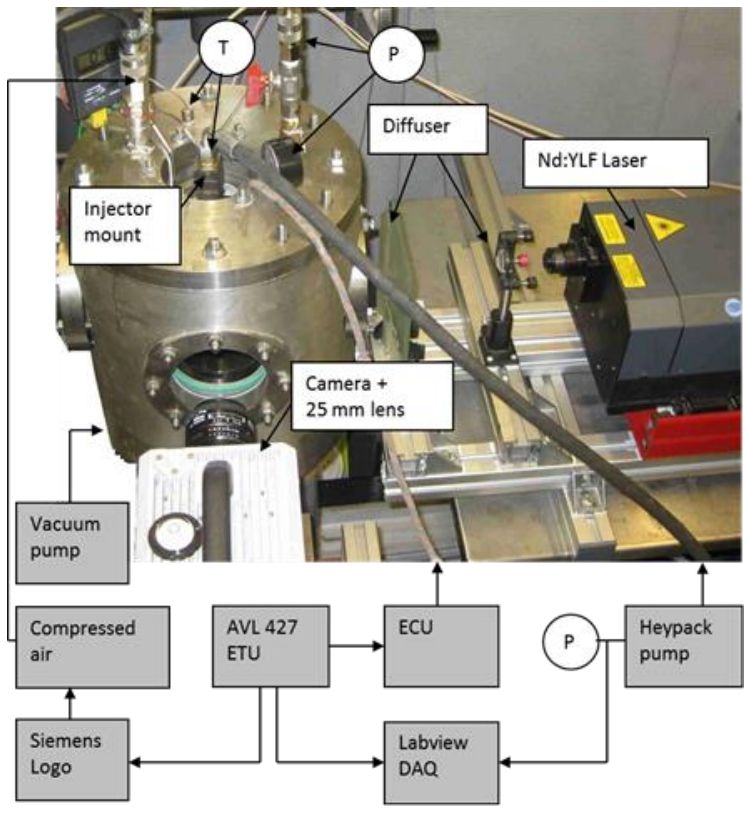

Figure 9. Spray image setup in quiescent chamber

The injector was rotated so that the symmetry axis was in the focal plane and images were taken mainly in the spray's side view. Additionally, a $45^{\circ}$ mirror was placed inside the chamber to obtain the injector footprint, using the Laser with and without sheet optics. Images were taken for 100 injection events, while footprint measurements were limited to 10 injections for cold gasoline only. The chamber was automatically purged (controlled by a Siemens LOGO PLC) of residual fuel with compressed air after each injection for a duration of $1.5 \mathrm{~s}$. Sufficient time was included to stabilize the air-flow in the chamber after purging before the next injection was triggered with a frequency of $0.2 \mathrm{~Hz}$. The chamber was attached to a vacuum pump for sub-atmospheric measurements at 0.5 bar air pressure, while it was open to ambient for 1 bar air pressure, representing full load in a naturally aspirated engine. The chamber and air temperature was at $20^{\circ} \mathrm{C}$. The fuel injector was brought to temperatures of $20^{\circ} \mathrm{C}$ or $80^{\circ} \mathrm{C}$ using a heating sleeve around the injector mounting block. The fuel was supplied by a Heypack pump and regulator system.

\section{Spray Imaging Processing}

Primary target of the processing was to obtain various angles describing the spray shape and to find the point of maximum penetration for each image. MATLAB code was developed to process automatically the large number of images. The definition of a suitable threshold was important to reduce ambiguity and ensure comparability between different fuels. The images obtained had a very high signal to noise ratio and included a distinct step change in image intensity in the presence of spray. The threshold of the spray was defined using the image histogram when no spray was present (i.e. during the time of spray delay). The histogram of the empty Page 5 of 19 images showed a single peak at an intensity level of 6 (of 255) and, with the exception of the nozzle tip, no values above 10 were found. The spray border was hence defined above a threshold of 15, which gave sufficient margin to the background noise.

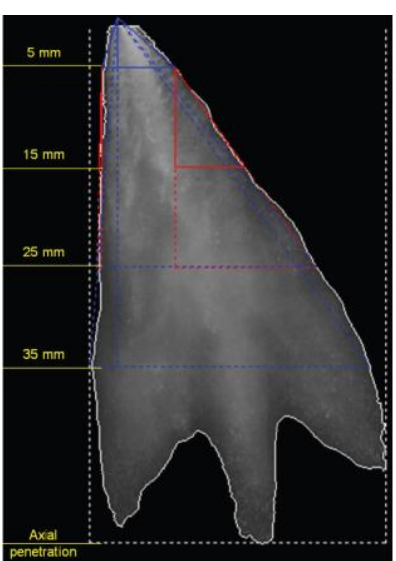

Figure 10. Spray image analysis locations.
Analysis of the images with spray showed that the pixel values at the defined spray border were mainly in the region of 18-30, with a steep increase from outside to inside the border, depending on the fuel. This gave confidence that little spray was lost due to the chosen threshold level. Reflections and glaring was reduced by covering the inner chamber walls with matt black foam mats. No further reflections were caused, with the exception of the nozzle tip itself. The general image processing consisted of:
- Raw image import into MATLAB as a matrix consisting of 8bit values (0-255).

- Background removal to reduce reflections.

- Threshold definition to distinguish spray and background.

- Binarisation of image to create background values of zero and spray values of 1 .

- Trace of the outline of the spray.

- Definition of the nozzle position.

- Finding the position of spray the furthest from the nozzle.

- Converting pixels into $\mathrm{mm}$.

- Calculation of the left and right hand side spray angles at the required distance from the nozzle.

- Addition of left and right hand side angles (overall angle).

- Superimposition of angles and outlining onto raw image for visualization, as shown in Figure 10.

Only the axial spray penetration, as well as the angle from the nozzle tip to $5 \mathrm{~mm}$ and to $25 \mathrm{~mm}$ past the nozzle are included in the presented work.

\section{Phase Doppler Anemometry (PDA) Setup}

The PDA system (TSI 5W Coherent Argon ion Laser with FSA4000 signal processor and TLN05-250 fiber probes) was arranged for $30^{\circ}$ off-axis forward scatter angle between transmitter and receiver as shown in Figure 11. The setup of channel $1(514.5 \mathrm{~nm})$ of the PDA system was used for the size measurements and vertical velocity measurements. It was set to $\sim 200 \mathrm{~mW}$, which was close to the maximum achievable Laser power.

The photo-multiplier voltage (PMT) was initially chosen using the D10 stabilization method. For this, the droplet size D10 of the gasoline spray was measured for increasing PMT voltages at maximum beam power to increase the signal to noise ratio. D10 was then plotted against PMT voltage, and the PMT selected for which the D10 began to stabilize. It was found that the D10 variation was very low in the interval between $350 \mathrm{~V}$ to $700 \mathrm{~V}$ and a value of $400 \mathrm{~V}$ was subsequently chosen. The TSI software's intensity validation, 
i.e. the check for invalid size measurements by signals from multiple particles, reflection, phase wrap and particles outside the $1 / \mathrm{e} 2$ beam waist diameter was activated. Channel 2 (488 $\mathrm{nm}$ ) was used to measure the horizontal droplet velocity. The maximum achievable Laser output power of $\sim 125 \mathrm{~mW}$ was used with a PMT voltage setting of $450 \mathrm{~V}$, selected to achieve maximum data rates. Table 2 summarizes the hardware and Table 3 important software settings.

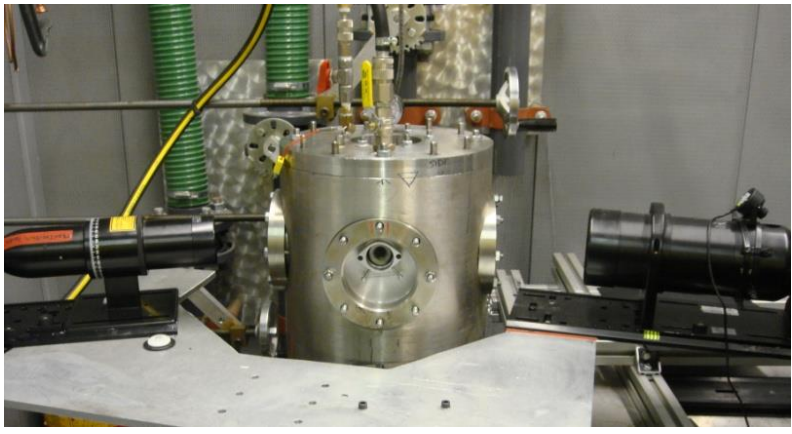

Figure 11. PDA transmitter and receiver setup.

A single spray plume was isolated to avoid the merging of the plumes that resulted in a very dense spray, particularly during hot collapsing conditions. To maintain the flow rate, the remaining six plumes were redirected using a metal funnel plate. Care had to be taken with the positioning of the funnel not to obstruct part of the bore but keeping the edges near to the nozzle hole and efficiently shielding the target region from neighboring plumes. For reasons of accessibility and easy setup, the most central plume was selected and the sheet metal funnel was carefully attached to the injector tip to redirect the remaining plumes. Figure 12 illustrates the overall spray cross section (left) and the extracted plume including the measurement locations (right). The measurements were taken at a vertical distance of $25 \mathrm{~mm}$ from the nozzle, along a straight horizontal line in intervals of $2 \mathrm{~mm}$, beginning in the chamber centre moving through the spray until signal drop out indicates the spray's border. Droplets were measured for 3.3 $\mathrm{ms}$ from the start of injection to obtain the droplets during the actual spray event (1.26 ms injection pulse) as well as after nozzle closure. The amount of injections measured was depending on the achievable data rate and varied between 100-400 injections until at least 10,000 valid droplets were measured at the central locations. Measurements in the plume's centre required more injections due to the issues typically associated with PDA in dense sprays, i.e. multiple droplets in the measurement volume, weakening of the Laser beam by obscuration and scatter.
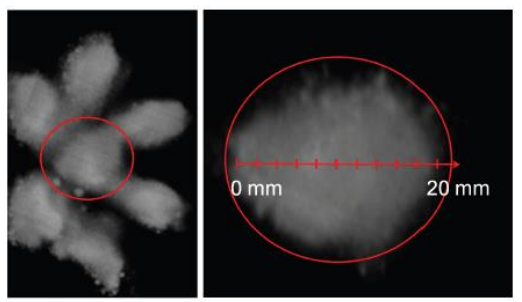

Figure 12. Footprint and single plume extraction for PDA.

Table 1. PDA system parameters.

\begin{tabular}{lcc}
\hline & Channel 1 & Channel 2 \\
\hline Wavelength [nm] & 514.5 & 488 \\
\hline Beam Diameter [mm] & 1.77 & 1.77 \\
\hline Beam Waist [ $\mu \mathrm{m}]$ & 92.5 & 87.8 \\
\hline Beam Separation [mm] & 20 & 20 \\
\hline Transmitter Focal Length [mm] & 250 & 250 \\
\hline Beam Half Angle [ $\left.{ }^{\circ}\right]$ & 2.3 & 2.3 \\
\hline Receiver Focal Length Front lens [mm] & 300 & 300 \\
\hline Receiver Focal Length Back lens [mm] & 250 & 250 \\
\hline Slit Aperture [ $\mu$ m] & 150 or 25 & 150 or 25 \\
\hline Fringe Spacing [ $\mu$ m] & 6.43 & 6.1 \\
\hline Number of Fringes & 14 & 14 \\
\hline Measurement Volume diameter $[\mu \mathrm{m}]$ & 93 & 2.2 \\
\hline Measurement Volume length $[\mathrm{mm}]$ & 2.3 & 40 \\
\hline Bragg Cell Frequency [MHz] & 40 & \\
\hline
\end{tabular}

Table 2. PDA software settings.

\begin{tabular}{lcc}
\hline & Channel 1 & Channel 2 \\
\hline Measurement & Size, Vertical & Horizontal \\
\hline PMT Voltage $[\mathrm{V}]$ & 400 & 450 \\
\hline Burst Threshold $[\mathrm{mV}]$ & 100 & 100 \\
\hline Band Pass Filter $[\mathrm{MHz}]$ & $10-65$ & $10-65$ \\
\hline Downmix Frequency $[\mathrm{MHz}]$ & 0 & 0 \\
\hline Diameter Range[ $\mu \mathrm{m}]$ & $0-100$ & - \\
\hline Maximum Intensity $[\mathrm{mV}]$ & 1000 & - \\
\hline Signal to Noise Ratio & Medium & Medium \\
\hline Measurement Duration $[\mathrm{ms}]$ & 3.3 & 3.3 \\
\hline
\end{tabular}

\section{Droplet Size Processing}

Analysis of the raw data was done in MATLAB where, as a first step, the velocity and size data was sorted into bins of $111 \mu \mathrm{s}$, i.e. $1 / 9000 \mathrm{~Hz}$, for each measurement location. Each bin was then analyzed regarding the average geometrical droplet diameter D10 and the Sauter mean diameter (SMD), the average bin velocity in horizontal and vertical direction as well as the number of droplets per bin and injection. A maximum droplet diameter threshold was chosen based on preliminary data analysis. At a stepwise increase of the threshold up to 50 $\mu \mathrm{m}$, an initially strong SMD increase was followed by a plateau region with very small increase in SMD gradient between 30 $\mu \mathrm{m}$ and $50 \mu \mathrm{m}$. After thresholds of $55-60 \mu \mathrm{m}$, the gradient increased significantly due to the bias of the SMD towards large droplets, even if few in number. Droplet size histograms also showed that very few droplets above 30-40 $\mu \mathrm{m}$ were found, and a threshold of $55 \mu \mathrm{m}$ was selected.

The results of the measurements for all positions are summarized for each test condition in PDA maps which give an overview of the SMD D10, spray velocity and spray density development versus time and position. Figure 13 explains the content of the maps. displaying the droplet size as SMD (small, inner rectangles) and D10 (large rectangles) averaged in bins of $0.111 \mathrm{~ms}$ bins for the spray position in $\mathrm{mm}$ from the chamber centre (vertical axis) and the time after start of injection (horizontal axis). Spray densities were defined by the amount of droplets acquired in each bin per injection and were superimposed in the form of contour plots. A measure of the total number of validated droplets for all injections per bin can be found by multiplying this number by the number of injections 
(typically 100-400), as mentioned earlier. Velocity flags calculated from the bin averaged vertical and horizontal velocity were also included, starting from the centre of the bins. Due to the complexity of the maps, only gasoline is presented in this format. In order to attach a single droplet size value for each fuel (used for the bar graphs presented later) the SMD over all injections and locations was used.

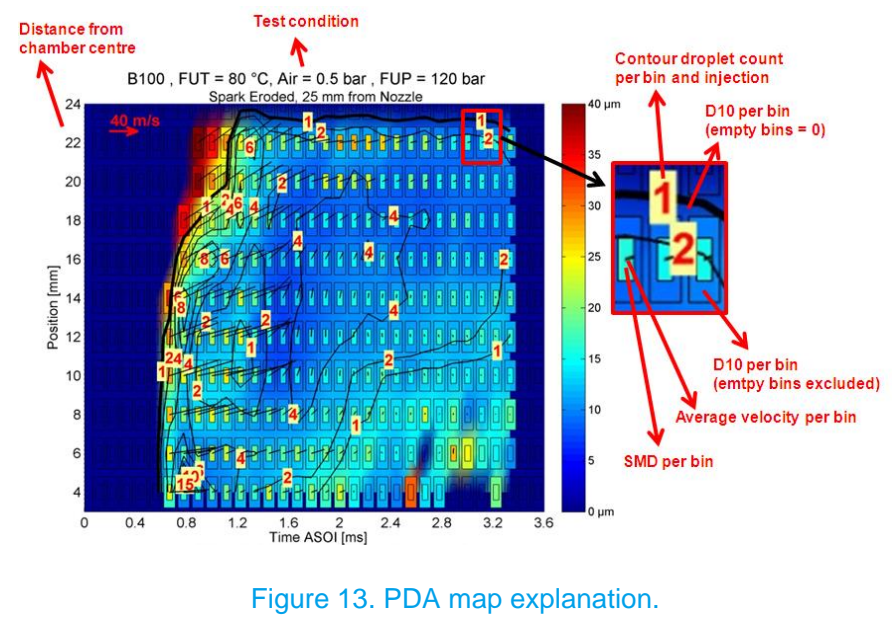

\section{Results and Discussion}

\section{Spray Imaging - Visual Analysis}

Figure 14 shows typical spray imaging with simultaneous side and bottom view through a $45^{\circ}$ mirror for gasoline at $20^{\circ} \mathrm{C}, 1$ bar. The image clearly shows better fuel atomization and spray dispersion for the Laser drilled injector.

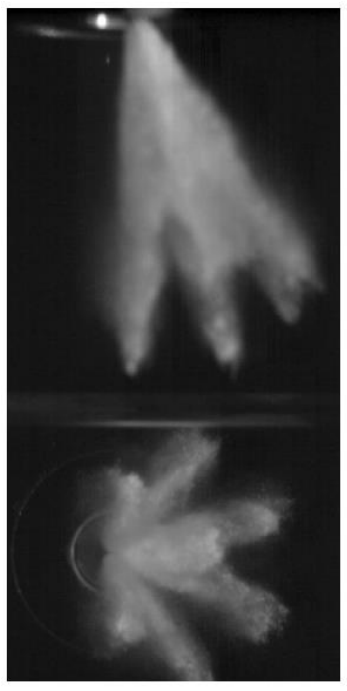

(a) Spark eroded

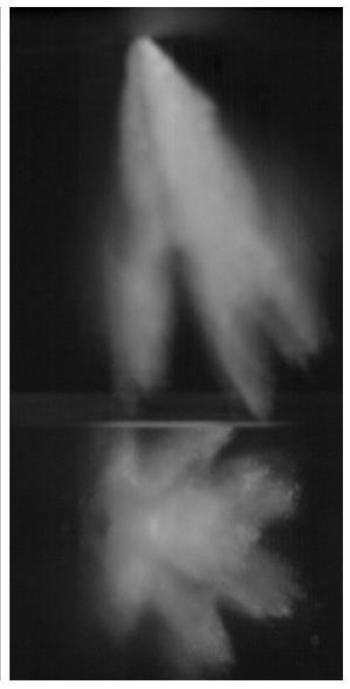

(b) Laser drilled
Figure 14. Simultaneous side and bottom view spray image of gasoline at $20^{\circ} \mathrm{C}$ injector temperature, 1 bar pressure at $0.888 \mathrm{~ms}$ ASOI for SE and LD injectors.

The spray images in Figures 15 to 18 show the spray development for a single image at $0.888 \mathrm{~ms}$ ASOI for gasoline, ethanol and butanol with the spark eroded nozzle above the
Laser drilled spray for the four test conditions. Complete image series showing the process of spray development have been included in the Appendix, Figures 29 and 30.

An observation from the outset for conditions of $20^{\circ} \mathrm{C}, 1 \mathrm{bar}$, is that the gasoline spray of the SE injector appeared with a slight delay compared to the LD injector, see Appendix Figure 26. This could partly explain the larger flow rates found for the LD injector in the mass flow analysis presented earlier. The individual spray cones are slightly more distinguishable for the SE injector, where three plume pairs (front plumes cover back plumes) seem to be present, but the central plume actually consists of three plumes as can be seen in Figure 7 which shows the side and bottom view of the gasoline injection. The LD injector also featured separate plumes which were slightly more dispersed and the overall spray was wider. The spray tip of the SE injector shows more clusters of larger droplets than the LD injector (to be quantified later). Also these large droplets contained much axial momentum causing the SE injectors tip penetration to make up for the initial delay and finally overtake the LD injector at $\sim 0.9 \mathrm{~ms}$ ASOI. The overall lower penetration of the LD injector, to be quantified and discussed in a separate section in detail later, can be beneficial in engine applications due to potential for reduced impingement on the piston crown and walls. The LD injector's overall spray pattern also indicates better fuel dispersion, clearly beneficial to the air-fuel mixture formation process.

For the alcohol sprays, the first notable difference to the gasoline sprays was that the initial delay was increased for both injectors; however, the effect was stronger for the SE nozzle. Such delays with alcohol fuelling have been previously observed with other multi-hole injectors, e.g. the 6-hole injector in [7-9] and are considered to stem from the higher fuel viscosity. Ethanol's spray tip droplets are visibly larger than gasoline's, especially for the SE injector. The LD injector also had a small delay in ethanol's appearance, but this was closer to gasoline's first arrival. Unlike for the gasoline case, the SE ethanol injection could not catch up or overtake the LD ethanol spray. Ethanol appeared again to be better atomized with the LD injector and large tip droplets were not as prominent. All effects observed for ethanol can be seen for butanol in an even more dominant form. The spray delay is distinctly increased by an additional $\sim 0.1 \mathrm{~ms}$ compared to ethanol in the SE injector but only slightly for the LD injector. As before, the LD injector seemed to exhibit better atomisation; the overall spray area was larger. At $20^{\circ} \mathrm{C}$ with 0.5 bar back pressure, sprays show generally higher penetration due to reduced drag and the fuels seem slightly more dispersed; see Figure 16, Appendix Figure 29.

Figures 17 and 18, as well as Appendix Figure 30, show spray images for injector temperature set to $80^{\circ} \mathrm{C}$. When increasing the temperature from $20^{\circ} \mathrm{C}$ to $80^{\circ} \mathrm{C}$, the vapor pressure of gasoline is significantly increased as shown earlier in Figure 2. As a result, the gasoline spray in both injectors shows signs typical of flash boiling; individual plumes are no longer discernible but a single spray structure is now present, propagating along the axis of the central plume. The mechanism of flash boiling and spray collapse of gasoline and other superheated fuels has previously been described in other publications, e.g. see [7-9] with 6-hole injectors but where the extent of collapse was less pronounced and individual plume structures were still visible at similar conditions. 


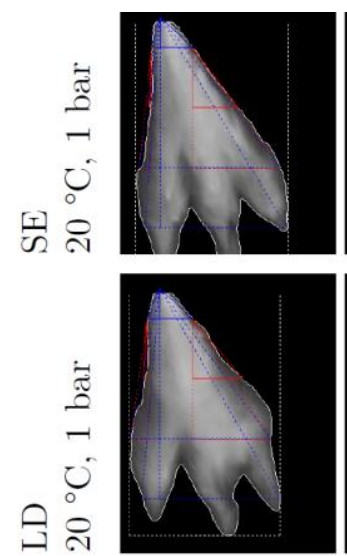

Gasoline
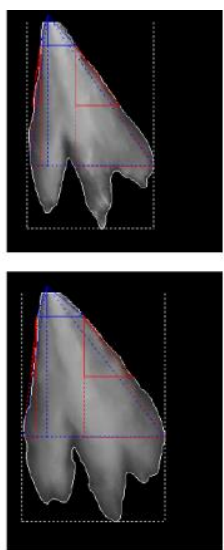

Ethanol
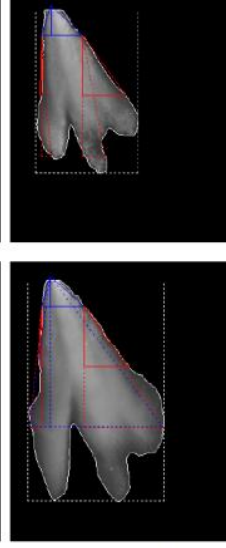

Butanol
Figure 15. Spray images, 1 bar air pressure, $20^{\circ} \mathrm{C}$ injector temperature, $0.888 \mathrm{~ms}$ ASOI.
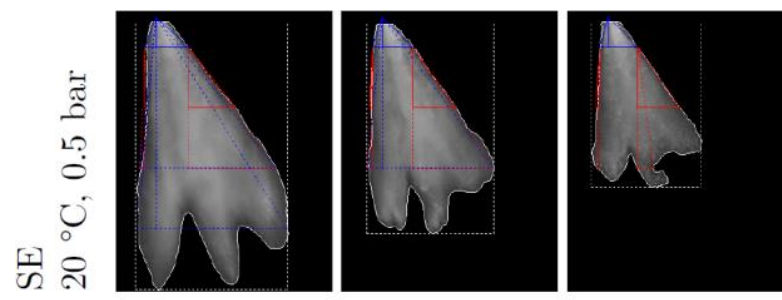

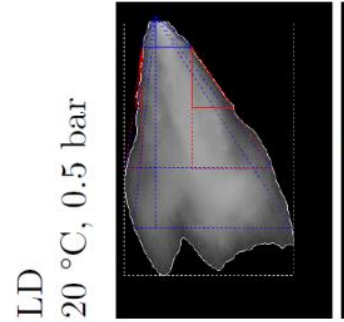

Gasoline

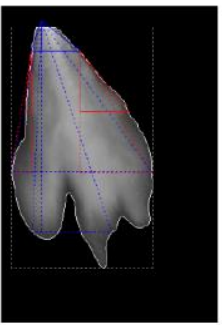

Ethanol

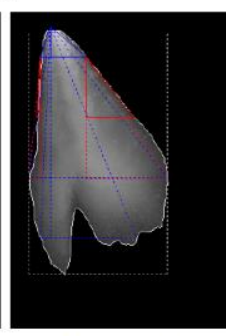

Butanol
Figure 16. Spray images, 0.5 bar air pressure, $20^{\circ} \mathrm{C}$ injector temperature, $0.888 \mathrm{~ms}$ ASOI.
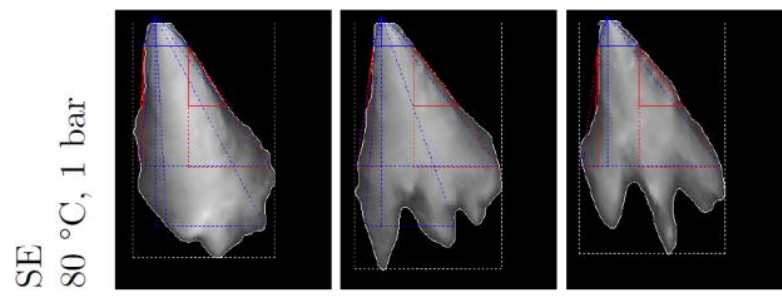

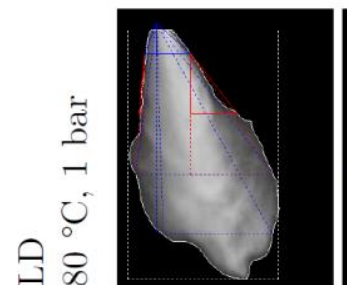

Gasoline

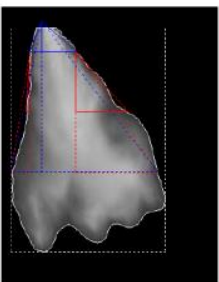

Ethanol

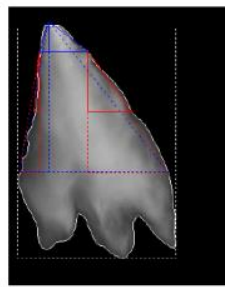

Butanol
Figure 17. Spray images, 1 bar air pressure, $80{ }^{\circ} \mathrm{C}$ injector temperature, $0.888 \mathrm{~ms}$ ASOI.
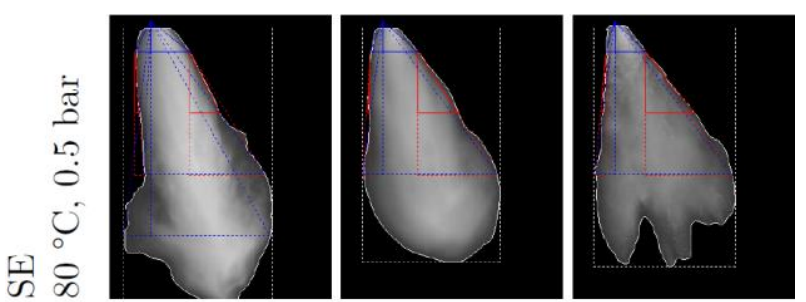

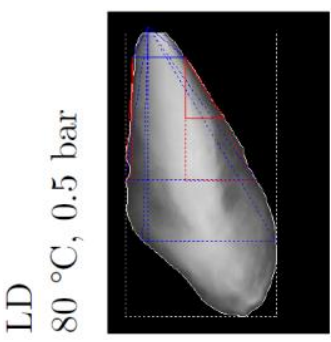

Gasoline

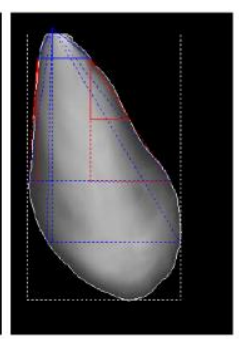

Ethanol

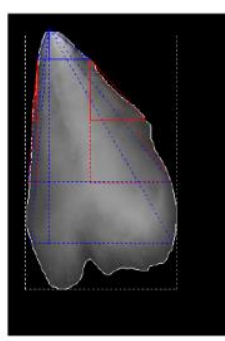

Butanol
Figure 18. Spray images, 0.5 bar air pressure, $80{ }^{\circ} \mathrm{C}$ injector temperature, $0.888 \mathrm{~ms}$ ASOI.

Flash boiling, despite the generation of small fuel droplets, is not necessarily desirable because of the associated destruction of the nominal spray pattern design and, at the extremes for specific hole arrangements, increased axial downwards momentum. The latter can cause poorer air-fuel mixing and stronger direct piston impingement. The gasoline spray with the LD drilled injector, appeared again earlier than with the SE nozzle. This time, it maintained its visibly higher penetration over the SE spray throughout the measurement and showed a wider spray area. Ethanol, even though just above its boiling point of $78^{\circ} \mathrm{C}$, is not flash-boiling at 1 bar ambient conditions, and the individual plume centers are still visible at the tip; collapse did not occur. At 0.5 bar however, the spray shape was closer to gasoline's which was even narrower and 'pointier'. As for ethanol, the spray delay that was visible at $20^{\circ} \mathrm{C}$ has largely disappeared for butanol at $80^{\circ} \mathrm{C}$, most likely due to viscosity reduction. The spray shape is otherwise reminiscent of the $20^{\circ} \mathrm{C}$ ethanol spray with clearly visible individual plumes and clusters of large droplets at the spray tip, especially for the SE injector. The reduced amount of large droplets in the spray tip of the LD spray was generally observed for all fuels and could explain recent claims for reduced particulate emissions (number and mass) with LD injectors [3], especially in combination with multiple injections and for designs with reduced flow rates.

For completeness, it is noteworthy that secondary injection events were observed for the LD injector just after initial closure, most likely caused by needle bounce. At $20^{\circ} \mathrm{C}$, see Figure 19, the nozzle showed first signs of closing after $\sim 1.67$ ms ASOI for gasoline and ethanol fuels, while butanol still seemed to be flowing freely at this point. One image later, the nozzle was fully closed for ethanol and butanol, while gasoline droplets exiting the nozzle were still visible. Two images after this, i.e. at $2 \mathrm{~ms} \mathrm{ASOI}$, there is a distinct second fuel quantity injected in the case of gasoline and a second closure event is discernible. At $80^{\circ} \mathrm{C}$, see Figure 20, the closing of the nozzle at $1.67 \mathrm{~ms}$ ASOI showed much finer droplets and better atomisation than at cold conditions, especially for gasoline and ethanol. The closing process was distinctly visible as the needle attenuation was reduced by the lower viscosity compared to $20^{\circ} \mathrm{C}$. Three image frames later, secondary fuel injection was present for all fuels, largest for gasoline, followed 
by ethanol and lastly by butanol for which only very few liquid ligaments were seen to escape from the nozzle; however, these appeared visibly larger in size than for gasoline and ethanol. High viscosity and surface tension effects are believed to reduce the needle movement and inhibit the flow through the gap created by the bouncing needle.
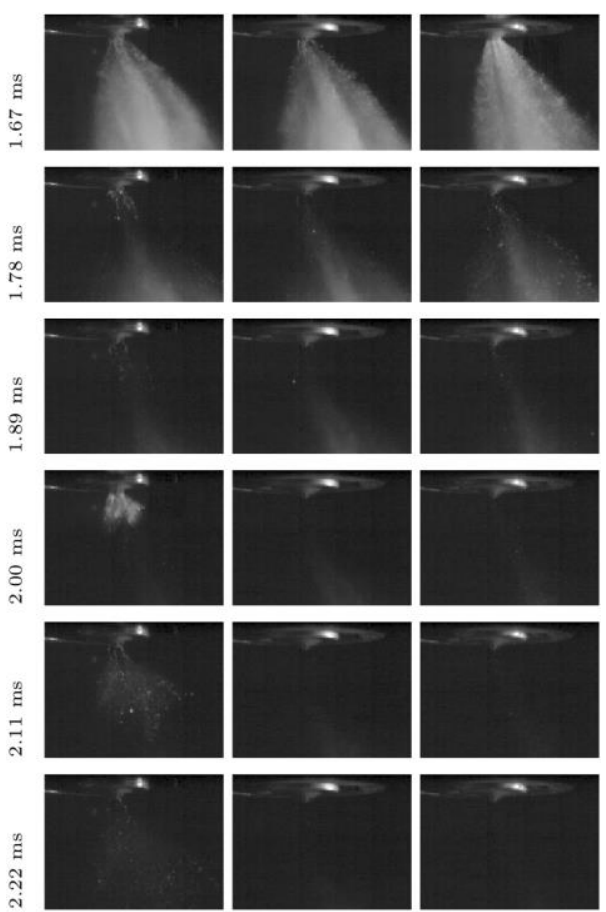

Ethanol

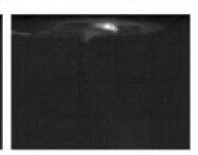

Butanol

Figure 19. LD needle bounce, $20^{\circ} \mathrm{C}$
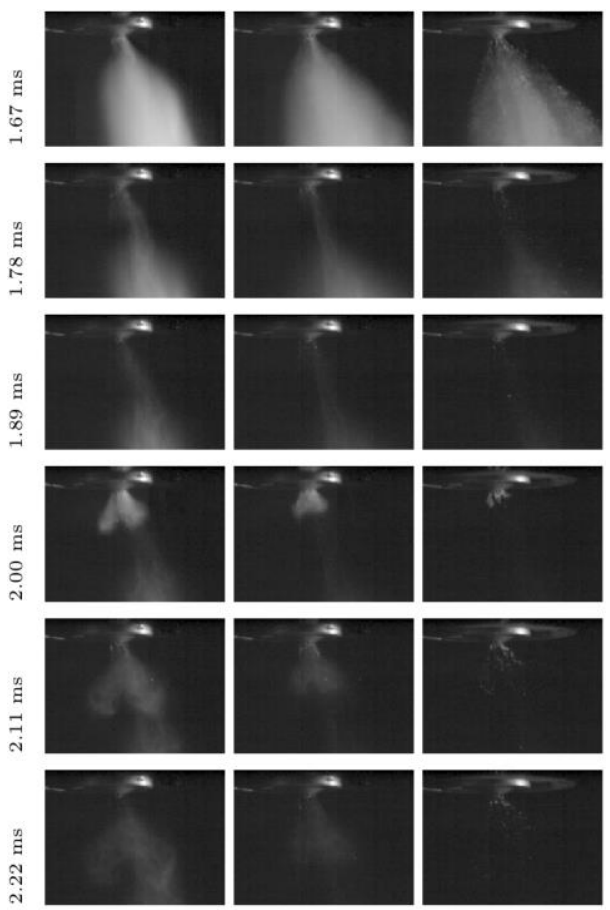

Gasoline

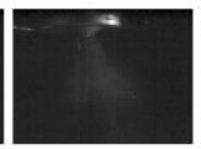

Ethanol

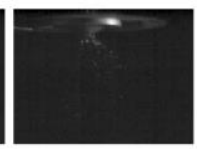

Butanol

Figure 20. LD needle bounce, $80^{\circ} \mathrm{C}$.
The exact origin of this bounce is not known and may well be a one-off prototype or production issue. However, it is clear that effects from needle bounce are undesirable as they are associated with large droplets which can be substantial in terms of mass and may cause increased emissions.

\section{Spray Penetration}

\section{Gasoline in LD and SE Nozzle}

The spray penetration graphs in Figure 21 A-D show straightaway the earlier spray appearance for gasoline with the LD injector (solid black lines), as discussed in the previous section. Additionally, it can be observed that at $20^{\circ} \mathrm{C}$ (A and $B)$, the initial penetration of the LD injector was higher than that of SE. The spray tip velocity was at first appearance approximately $100 \mathrm{~m} / \mathrm{s}$ for both nozzles (calculated by the gradient of the penetration curve) and reduced almost linearly from the onset of the spray for the LD injector. In contrast, the SE injector maintained the spray tip velocity during the initial 0.3-0.4 ms after appearance until a steep velocity reduction followed. Reasons for this could be manifold, e.g. differences in effective aerodynamic forces for the LD injector due to its wider dispersion, or different effects from pressure drop and developing in-nozzle cavitation with ongoing injection.

At $1 \mathrm{bar}, 80^{\circ} \mathrm{C}$ (Figure $21 \mathrm{C}$ ), initial spray tip velocities were $10-15 \%$ lower than at $20{ }^{\circ} \mathrm{C}$. The collapsed spray of the flash boiling fuels exhibited higher penetrations and velocities probably due to the smaller drag experienced at the narrower spray tip and increased downwards momentum from the merged plumes. Such a strong increase in penetration can play a major part in poor mixing with typical issues such as increased impingement on cylinder walls and piston and poorer distribution due to the more compact spray in addition to droplet agglomerations. This could well offset the positive aspects of flash boiling which generally causes smaller droplet sizes and good atomisation at nozzle exit.

The slightly larger penetration of the LD injector can have similar deleterious effects but if seen in the context of this injector's larger mass flow rate, the injector pulse length would be reduced to achieve the same injection quantity to that of the $\mathrm{SE}$ and thus also achieve a lower penetration.

\section{Alcohols in LD and SE Nozzle}

The spray penetration graphs at 1 bar, $20^{\circ} \mathrm{C}$ (Figure $21 \mathrm{~A}$ ), emphasize the delay in spray appearance for the higher viscous fuels. It was $\sim 0.1 \mathrm{~ms}$ for ethanol and $\sim 0.2 \mathrm{~ms}$ for butanol compared to gasoline in the SE injector. The differences almost disappeared for the LD injector and both alcohols were only slightly delayed by $0.025-0.05 \mathrm{~ms}$. Ambient pressure reduction to 0.5 bar (Figure $21 \mathrm{~B}$ ), didn't affect the penetration significantly, but the spray tip velocity increased with initial values $\sim 5 \%$, more than for the 1 bar sprays. The spray tip velocity reduced much quicker, almost linearly with a gradient of $120 \mathrm{~m} / \mathrm{s}$ per $\mathrm{ms}$ for the LD injector, while the initial velocity was maintained for longer with the SE injector (and with a slower decline for the first $0.3 \mathrm{~ms}$ after appearance before a strong deceleration set in). This indicates larger droplets which carry more momentum for the SE injector at nozzle exit and early spray penetration. 

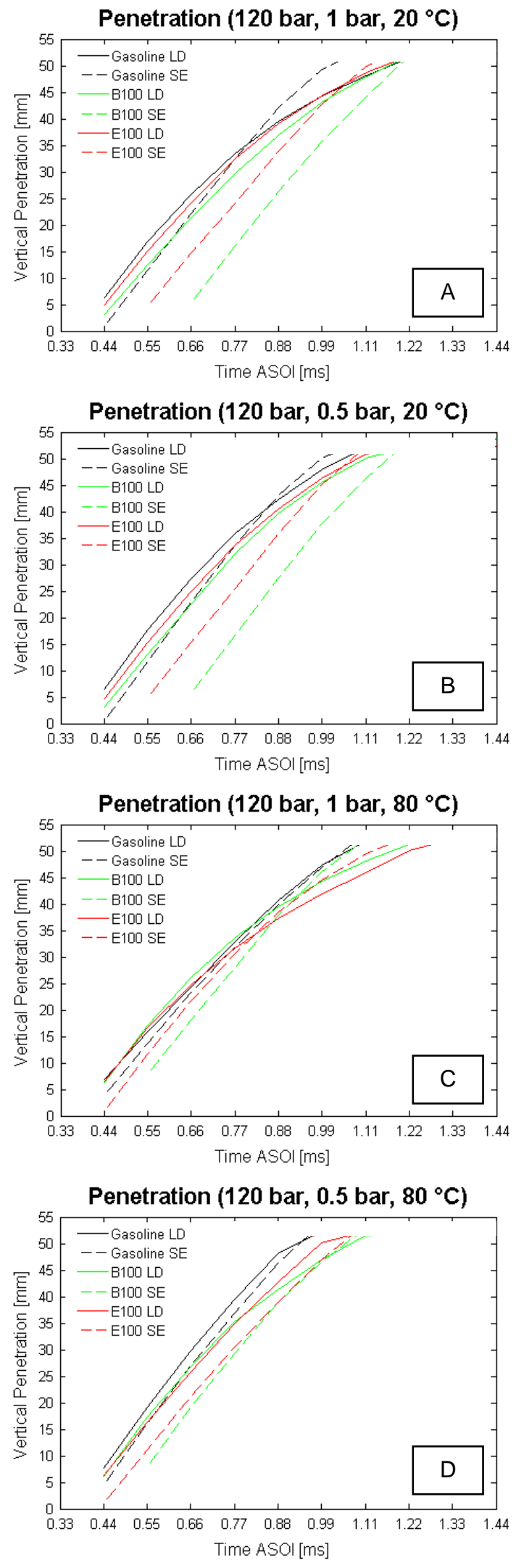

Figure 21. Spray penetration.
At 1 bar, $80^{\circ} \mathrm{C}$ (Figure $21 \mathrm{C}$ ), gasoline showed the largest penetration due to spray collapse and a more constant tip velocity, probably due to the small spray cross section and reduced overall drag. The SE injector now showed a faster spray tip velocity decline, likely caused by smaller droplets. Butanol, with its still very large droplets was not affected to the same extent, but the strong viscosity reduction due to the temperature increase resulted in a much earlier spray appearance. The case for the LD injector was similar, with gasoline collapsing and with butanol's initial delay having disappeared. The average deceleration for gasoline was 58 $\mathrm{m} / \mathrm{s}$ per $\mathrm{ms}$ for the SE and $76 \mathrm{~m} / \mathrm{s}$ per $\mathrm{ms}$ for the LD injector primarily due to better dispersion.

At 0.5 bar, $80^{\circ} \mathrm{C}$ (Figure $21 \mathrm{D}$ ), flash boiling and collapse of the sprays also occurred with ethanol, but butanol was least affected. The penetration and tip velocities increased significantly for pure gasoline, but also for ethanol, compared to 1 bar. Deceleration was still stronger for the LD injector with $76 \mathrm{~m} / \mathrm{s}$ per ms compared to $54 \mathrm{~m} / \mathrm{s}$ per $\mathrm{ms}$ for the SE injector. Penetrations were generally highest at this condition due to the low back pressure creating smaller resistance combined with the mechanism of increased vertical momentum from spray collapse.

The injection events showed good repeatability with small shotto-shot variability. The maximum standard deviation in penetration was about $1.5 \mathrm{~mm}$. Additionally, the spray tip velocity showed standard deviations up to $5 \mathrm{~m} / \mathrm{s}$ and $3 \mathrm{~m} / \mathrm{s}$ for the SE and LD injectors, respectively; the highest values corresponded to the low temperature of $20^{\circ} \mathrm{C}$.

\section{Spray Angle at $5 \mathrm{~mm}$}

\section{Gasoline in LD and SE Nozzle}

Figures $22 \mathrm{~A}-\mathrm{D}$ show the $0-5 \mathrm{~mm}$ angle development at the four test conditions. Generally, fuel appeared at the measurement location $5 \mathrm{~mm}$ past the nozzle tip between 0.44 $\mathrm{ms}$ and $0.55 \mathrm{~ms}$ ASOI, slightly earlier for the LD injector. After an initial peak, the sprays relax quickly and maintain a constant angle for the duration of the injection, until the end of the spray's development during nozzle closing at $1.5 \mathrm{~ms}$ ASOI. At closure, the angle reduced more so for the lower back pressure condition of 0.5 bar and much faster at the hot condition of $80^{\circ} \mathrm{C}$ where the fuel viscosity is believed to cause less resistance to nozzle closure. At $20^{\circ} \mathrm{C}$, the angle is about $5-7^{\circ}$ larger for the LD injector, indicating better initial droplet breakup. The difference reduced at $80^{\circ} \mathrm{C}$, where the LD injector had only $2^{\circ}$ wider sprays. The angle increase when raising the temperature to $80^{\circ} \mathrm{C}$ was found to be of the order of $4-10^{\circ}$ for the SE injector, while the LD injector only featured minimal increase at 1 bar, but a significant $7^{\circ}$ increase at 0.5 bar due to rapid expansion of the spray at the nozzle exit from flash boiling effects. 


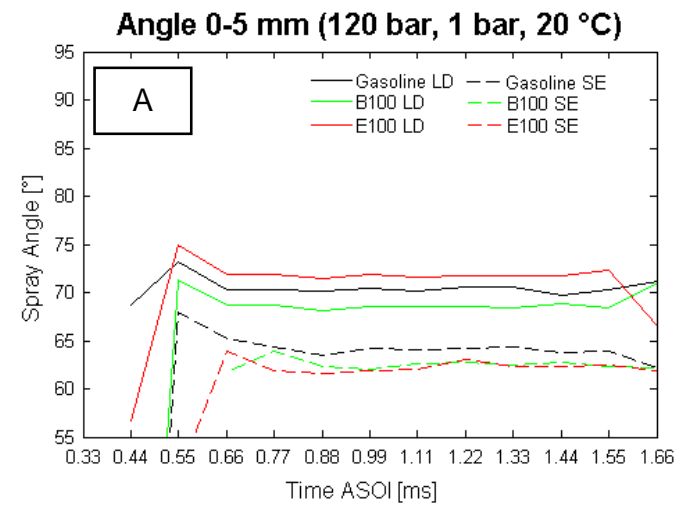

Angle $0-5 \mathrm{~mm}\left(120 \mathrm{bar}, 0.5 \mathrm{bar}, 20^{\circ} \mathrm{C}\right)$

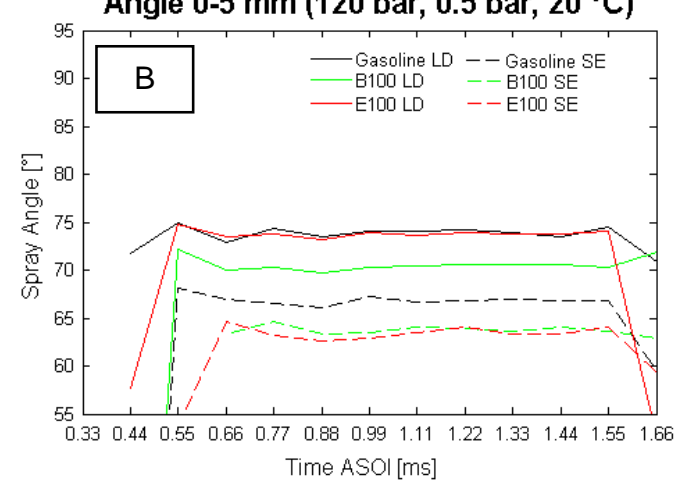

Angle $0-5 \mathrm{~mm}\left(120 \mathrm{bar}, 1 \mathrm{bar}, 80^{\circ} \mathrm{C}\right)$

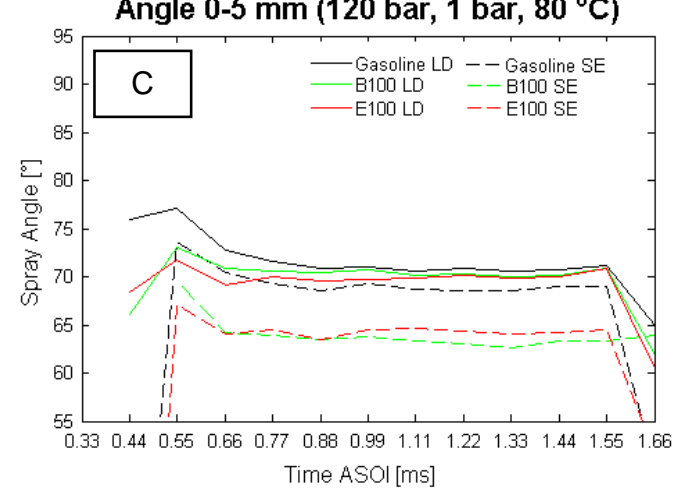

Angle $0-5 \mathrm{~mm}\left(120 \mathrm{bar}, 0.5 \mathrm{bar}, 80^{\circ} \mathrm{C}\right)$

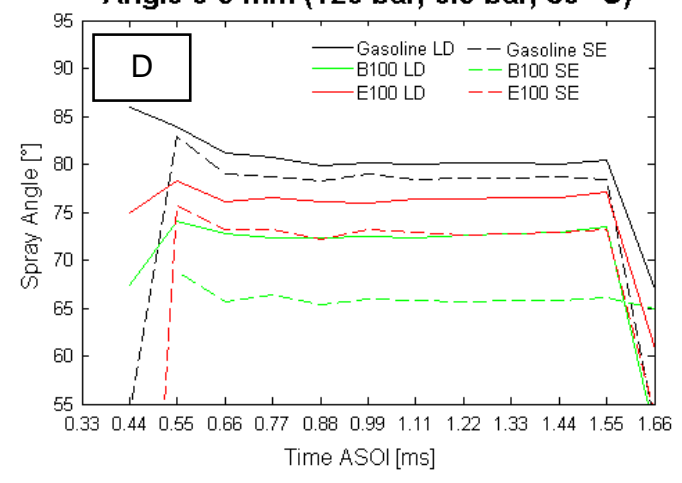

Figure 22. Spray angle at $5 \mathrm{~mm}$ from nozzle.

\section{Alcohols in LD and SE Nozzle}

For the alcohols, all $0-5 \mathrm{~mm}$ spray angles at $20^{\circ} \mathrm{C}, 1$ bar (Figure $22 \mathrm{~A}$ ) were within $2^{\circ}$, just below $65^{\circ}$ for the SE and within $4^{\circ}$, just around $70^{\circ}$ for the LD injector. Standard deviations were very low, low shot to shot variability, and were in the region of $1.5-2.5^{\circ}$ for all fuels.

Reducing the back pressure to 0.5 bar (Figure $22 \mathrm{~B}$ ) increased the $0-5 \mathrm{~mm}$ angle for both injectors by $2^{\circ}$ and resulted in slightly increased spread between fuels. Ethanol and butanol were mirroring each other in the SE nozzle, but the LD nozzle featured a difference of $4^{\circ}$, with ethanol having largest and butanol lowest angle.

This was similar when increasing the fuel temperature to $80^{\circ} \mathrm{C}$ at 1 bar (Figure $22 \mathrm{C}$ ), but the differences between fuels became more obvious. Both injectors showed a large angle just after first appearance at the measurement location followed by a slight relaxation and a very stable angle plateau for the duration of the spray. With the SE injector, especially gasoline (having the highest vapor pressure) separates away towards larger angles indicating the onset of flash boiling. The LD injector was slightly different, showing a strong effect for gasoline only for the first $\sim 0.1-0.2$ ms after spray appearance, before it reduced back to the levels of the alcohols.

Reducing the pressure at $80^{\circ} \mathrm{C}$ to 0.5 bar (Figure $22 \mathrm{D}$ ) resulted in increased angles for gasoline and ethanol with both injectors. Gasoline was still affected the strongest and featured angles of $\sim 80^{\circ}$ for the SE and $\sim 82^{\circ}$ for the LD nozzle. Ethanol which was also subject to strong superheat was also lifted to $\sim 74^{\circ}$ and $\sim 76^{\circ}$, respectively. Butanol remained unaffected.

\section{Spray Angle at $25 \mathrm{~mm}$}

\section{Gasoline in LD and SE Nozzle}

The first interesting observation for the spray angle at $25 \mathrm{~mm}$ past the nozzle (Figure 23 A-D) is that the sprays of both injectors appeared at a similar time, suggesting that the initially earlier spray appearance at the nozzle tip of the LD injector was compensated for by a higher spray tip velocity of the SE injector. This behavior was with the exception of the $80^{\circ} \mathrm{C}$ fuel sprays into 0.5 bar back pressure where the LD spray appeared about one image earlier $(0.11 \mathrm{~ms})$. The shape of the angle's development in time, unlike the $5 \mathrm{~mm}$ angle, did not feature a stable plateau but developed to a peak value and successively reduced during injection for all cases, except at the strongest flash boiling conditions in Figure $23 \mathrm{D}$ (0.5 bar, $80^{\circ} \mathrm{C}$ ) where strong collapse occurred. On this occasion the angle was almost constant during injection.

The LD injector had larger angles than the SE injector, confirming better spray dispersion. The difference between the injectors was of the order of $4-5^{\circ}$ at $20^{\circ} \mathrm{C}$ and $1-4^{\circ}$ at $80^{\circ} \mathrm{C}$, generally lower for the 0.5 bar back pressure setting. 


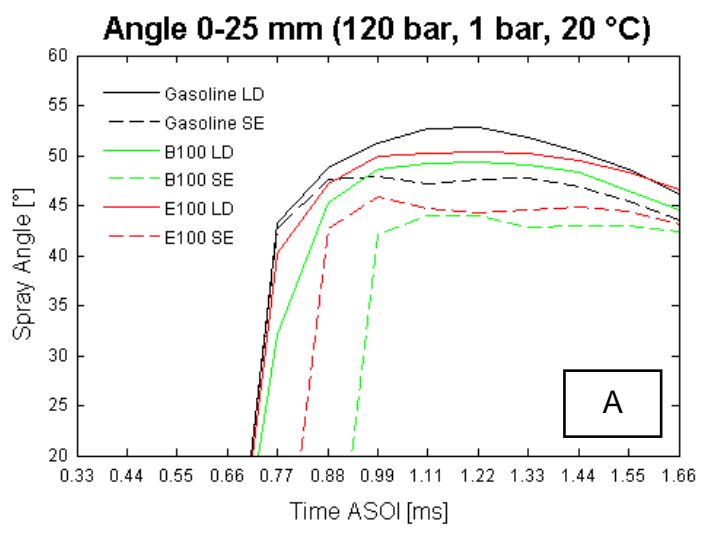

Angle $0-25 \mathrm{~mm}\left(120 \mathrm{bar}, 0.5 \mathrm{bar}, 20^{\circ} \mathrm{C}\right)$

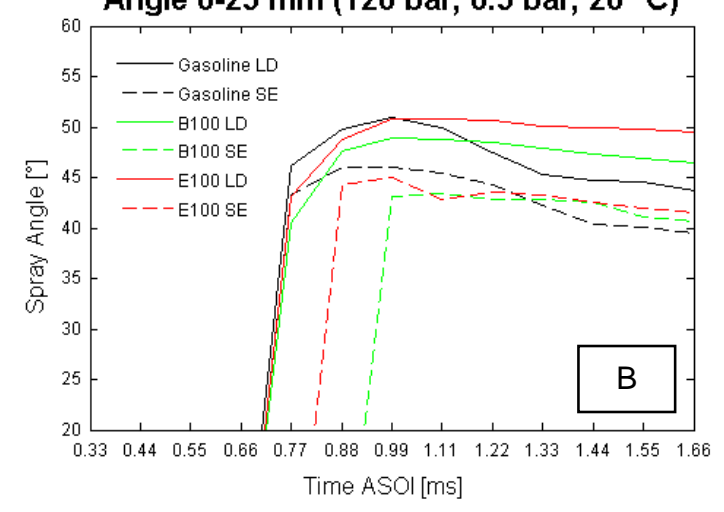

Angle $0-25 \mathrm{~mm}\left(120 \mathrm{bar}, 1 \mathrm{bar}, 80^{\circ} \mathrm{C}\right)$

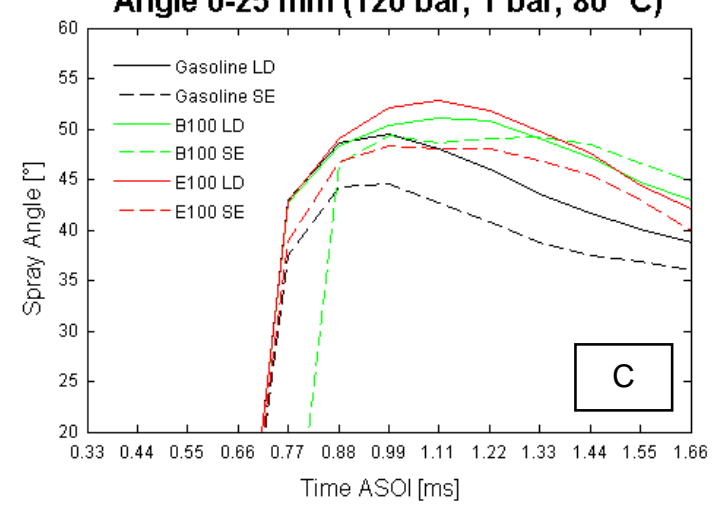

Angle $0-25 \mathrm{~mm}\left(120 \mathrm{bar}, 0.5 \mathrm{bar}, 80^{\circ} \mathrm{C}\right)$

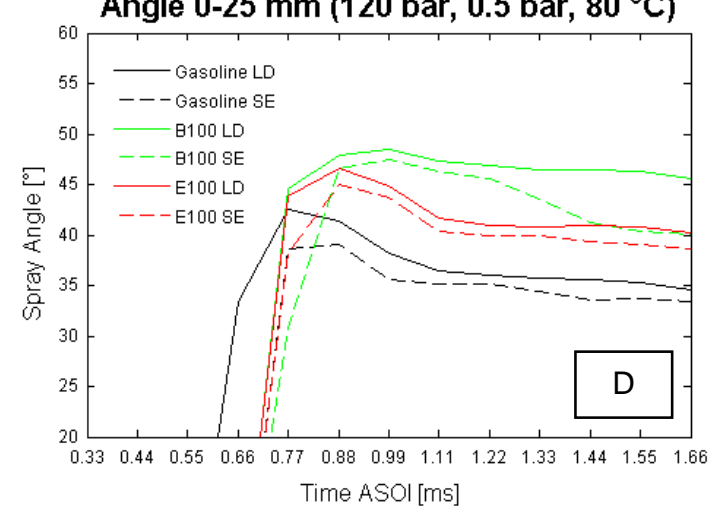

Figure 23. Spray angle at $25 \mathrm{~mm}$ from nozzle.

\section{Alcohols in LD and SE Nozzle}

At the base condition of 1 bar back pressure, $20^{\circ} \mathrm{C}$ fuel temperature (Figure $23 \mathrm{~A}$ ), the angles at $25 \mathrm{~mm}$ from the nozzle were between $42^{\circ}$ and $47^{\circ}$ for the SE injector and $48^{\circ}$ and $52^{\circ}$ for the LD injector, with butanol being lowest and gasoline highest. Most prominent difference between the two injectors was that the fuels with high viscosity arrived significantly delayed at the point of measurement for the SE injector, where an almost stable angle with only a slight successive reduction with ongoing injection duration was established, while the LD injector's sprays appeared almost simultaneously, with butanol trailing slightly. A much 'curvier' shape is obtained with a larger maximum value than for the SE injector. Looking at the spray images, this can be related to recirculation structures breaking away from spray tip, which was more dominant for the LD injector. This recirculation region was also present at 0.5 bar back pressures and cold fuels $(B)$, but occurred later in space so that was less visible in the spray's graphs and the angles reduced for both injectors by $2-3^{\circ}$. Gasoline still showed signs of the recirculation in the LD injector.

At $80^{\circ} \mathrm{C}, 1$ bar (Figure $23 \mathrm{C}$ ) recirculation zones were equally present with both injectors and gasoline featured a significantly smaller spray angle than the alcohols in the SE nozzle, in agreement with findings with a 6-hole injector in [8]. The LD injector already showed collapse and merging of individual plumes with gasoline fuelling, but also featured stronger recirculation than the gasoline spray of the SE injector, so that the actual angles were similar for both injectors. At $80^{\circ} \mathrm{C}, 0.5$ bar, gasoline and ethanol finally merged into one distinct single spray structure, without any traces of the individual plumes remaining. Gasoline had the lowest angles with $35^{\circ}$ and $37^{\circ}$ for the SE and LD injector respectively (Figure $23 \mathrm{D}$ ). Some recirculation was still visible, more so for the LD injection. Ethanol's collapse was not as pronounced and the resulting angles were between $40-42^{\circ}$. Butanol still maintained some plume separation with the SE injector exhibiting a gradual angle reduction from $47^{\circ}$ to $40^{\circ}$ during injection; in contrast the LD nozzle resulted in larger angles of $47^{\circ}$ to $45^{\circ}$. Those fuels with largest $5 \mathrm{~mm}$ angles (due to flash boiling) resulted in strongest spray merging and collapse at $25 \mathrm{~mm}$ past the nozzle.

The standard deviation of the angle calculation was dependent on the ambient pressure for both injectors. It was lowest for 0.5 bar back pressures with values in the region of $1-1.5^{\circ}$ for both injectors. 1 bar back pressures seemed to increase the variability significantly and standard deviations of $1-4^{\circ}$ were calculated, with the lowest values corresponding to alcohols. It is believed that higher air pressure results in more variability due to more dominant transient effects during injection. The generally wider spray angles found for the LD injector and the smaller delay visible for the measurements, further support the previous observations of better spray dispersion for this nozzle and the reduced susceptibility of the spray's geometry to fuel properties. 


\section{Droplet Sizing Results}

\section{Gasoline in LD and SE Nozzle}

The spray maps in Figures 24 for the SE and Figure 25 for the LD injector, respectively, refer to gasoline fuel droplets obtained by PDA at a vertical location $25 \mathrm{~mm}$ from the nozzle. Subfigure A contains the $20^{\circ} \mathrm{C}, 1$ bar condition, B the $20^{\circ} \mathrm{C}$, 0.5 bar, whilst $C$ and $D$ show the results for $80^{\circ} \mathrm{C}$ fuel temperature at 1 bar and 0.5 bar air pressure, respectively. As explained earlier in Figure 13, these maps contain the droplet size as SMD and D10, velocity and burst count with respect to time after injection (horizontal axis) and against the position in the spray in $\mathrm{mm}$ from the chamber centre (vertical axis). It can be observed that the droplets arriving first at the measurement location were the largest in size, with SMD up to $30 \mu \mathrm{m}$ at 20 ${ }^{\circ} \mathrm{C}$ and up to $18 \mu \mathrm{m}$ at $80{ }^{\circ} \mathrm{C}$. Differences between SMD and D10 for individual bins demonstrate the effect of few very large droplets on SMD, as SMD is biased stronger towards the larger diameters than D10. Large droplets were also found at the most outwards spray locations, but these were low in numbers as indicated by low droplet counts. The plume centre region is represented at locations of $6-12 \mathrm{~mm}$ from the chamber centre. Here, the droplet bins had a large SMD, 15$25 \mu \mathrm{m}$ for $20^{\circ} \mathrm{C}$ and $15-20 \mu \mathrm{m}$ for $80^{\circ} \mathrm{C}$, with the LD injector showing slightly larger droplets and high velocities, along with reduced droplet count. The latter is believed to be due to denser spray and possibly droplet agglomerations. The droplet velocities reduced quickly after closure of the nozzle $(\sim 1.8 \mathrm{~ms}$ ASOI). At late timings after $2.8 \mathrm{~ms}$ ASOI, the droplets at the former spray centre showed a slight size increase (more so for $20^{\circ} \mathrm{C}$ ), possibly due to coalescence, but in the case of the LD injector probably from effects of the needle bounce process described earlier.

When the SMD was calculated for each measurement location by averaging in time, at 1 bar air pressure and $20^{\circ} \mathrm{C}$ fuel temperature (Figure $24 \mathrm{~A}$ and $25 \mathrm{~A}$ ), the SMD ranged between 16-18 $\mu \mathrm{m}$ for both injectors. The large droplets at the sprays border were more prominent at 1 bar than at 0.5 bar air pressure (Figures $24 \mathrm{~B}$ and $25 \mathrm{~B}$ ). At $80^{\circ} \mathrm{C}$ (Figures 24 and $25, C$ and D), the droplet size was reduced to levels of 12-14 $\mu \mathrm{m}$ and also featured a larger plume width, believed to be due to flash boiling effects and the wider nozzle exit angles quantified earlier.

The droplet velocities during open nozzle peaked at about 80 $\mathrm{m} / \mathrm{s}$ for 0.5 bar back pressure and were slightly higher for 20 ${ }^{\circ} \mathrm{C}$ than for $80^{\circ} \mathrm{C}$. At 1 bar back pressures, the axial velocities reduced to $50 \mathrm{~m} / \mathrm{s}$ in the spray core for both temperatures and were larger by $\sim 10 \%$ for the LD than the SE injector. The horizontal velocities were measured to be between 15-20 m/s and were again higher for the 0.5 bar back pressure, slightly larger for the LD than the SE nozzle. Overall, the droplet velocities of the two injectors followed similar trends to those described earlier for the spray penetration.

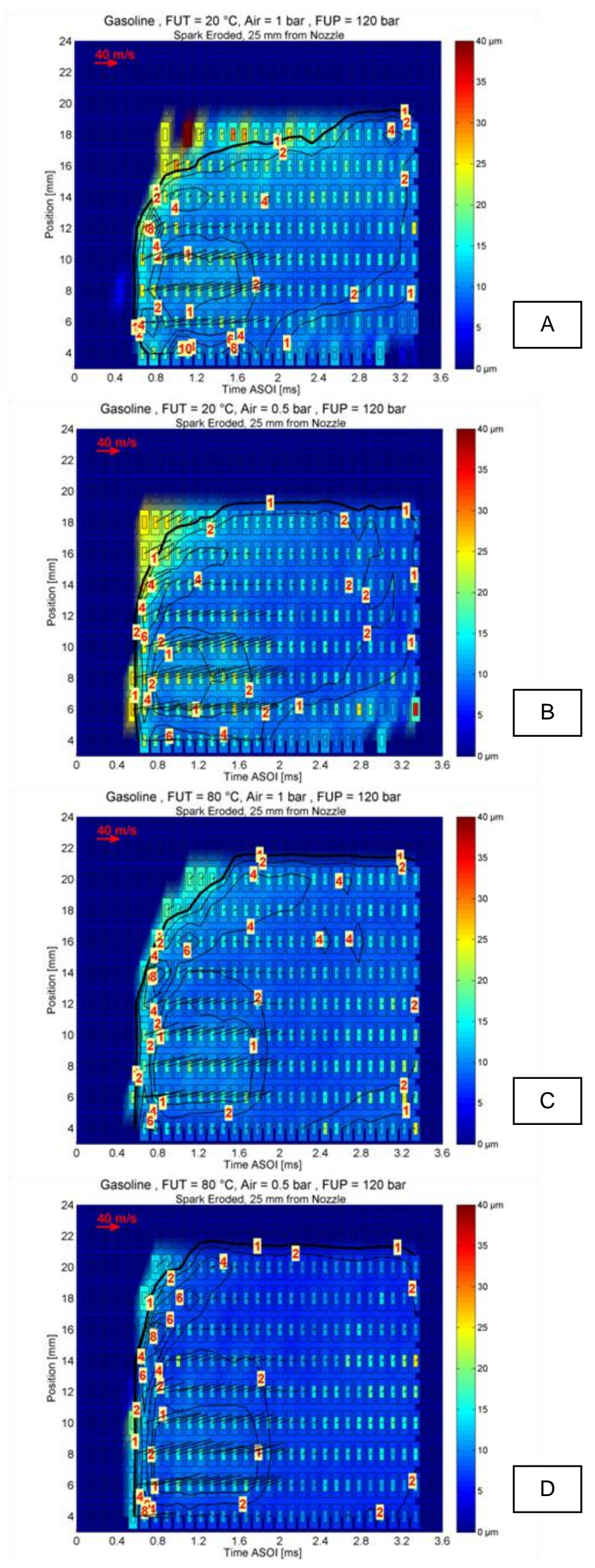

Figure 24. PDA maps, SE injector with gasoline. 


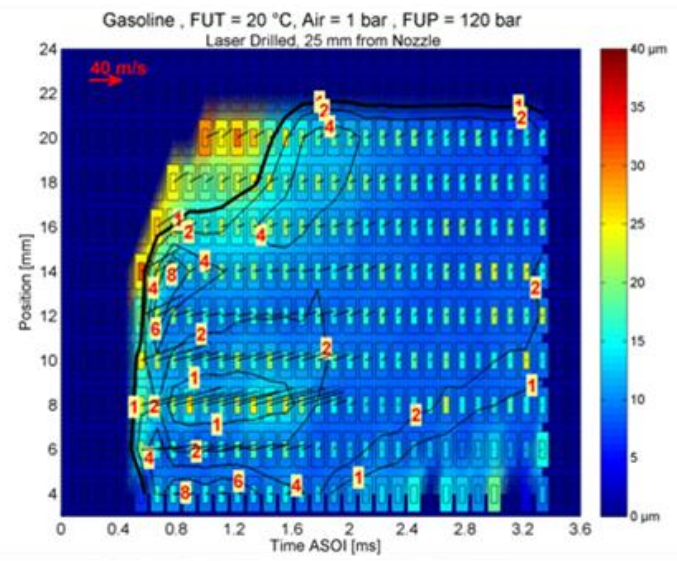

Gasoline, FUT $=20^{\circ} \mathrm{C}$, Air $=0.5$ bar, FUP $=120$ bar

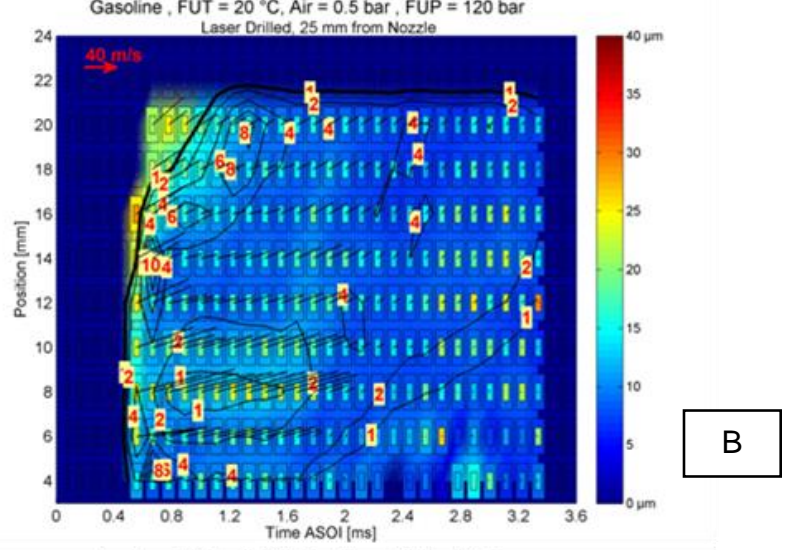

Gasoline, FUT $=80^{\circ} \mathrm{C}$, Air $=1$ bar, FUP $=120$ bar

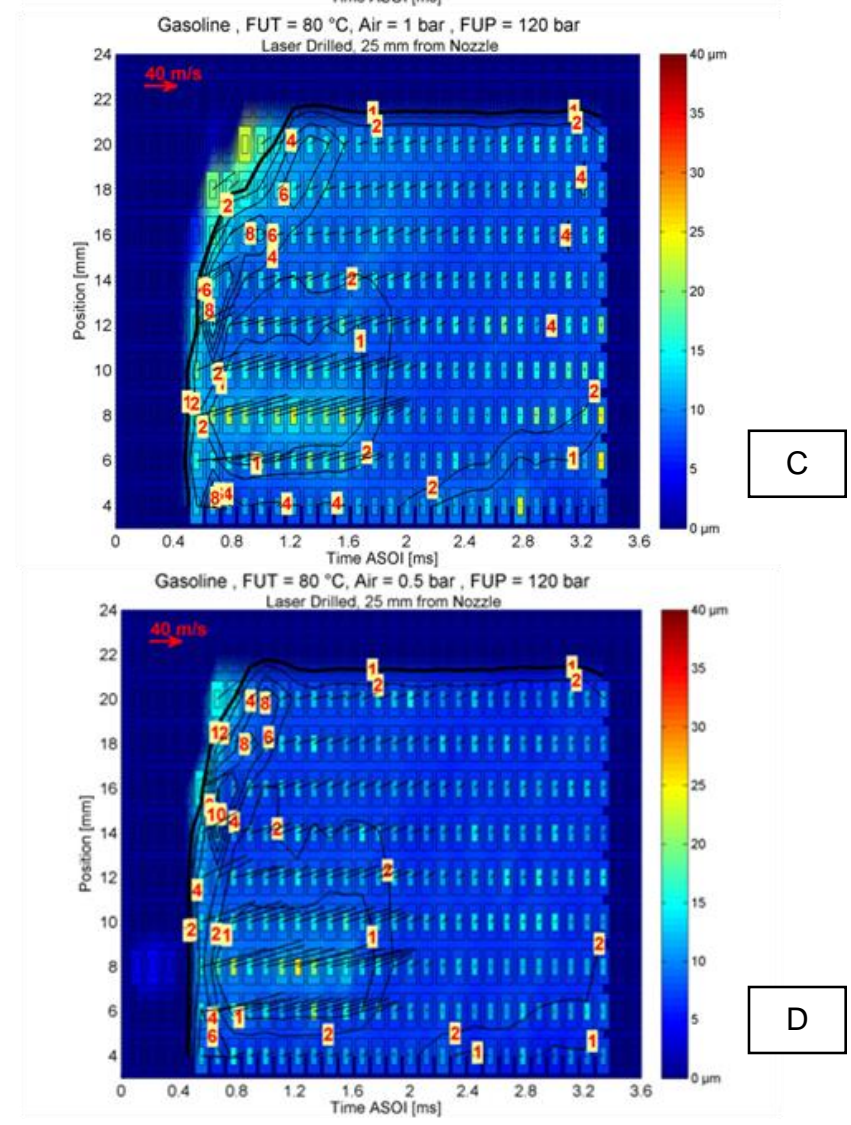

Figure 25. PDA maps, LD injector with gasoline.
The most obvious differences between the SE and LD injectors was the distinctly wider spray for the LD injector at $20^{\circ} \mathrm{C}$, in clear agreement with the observations made by spray imaging. This wider fuel dispersion could positively affect the air fuel mixture at cold-start conditions and possibly particulate related emissions. The LD injector's spray width was similar at $20^{\circ} \mathrm{C}$ and $80^{\circ} \mathrm{C}$. The LD injector exhibited marginally smaller SMD than the SE with 0.5 bar back pressure at both $20^{\circ} \mathrm{C}$ and 80 ${ }^{\circ} \mathrm{C}$ injector temperatures. Similarly marginal differences were observed between the two injectors at 1 bar, with the LD nozzle exhibiting submicron smaller droplets at $80^{\circ} \mathrm{C}$ and larger at $20^{\circ} \mathrm{C}$ (when averaged in space and time). It needs also to be highlighted here that, as observed earlier by imaging, the clustered droplets at the spray tip upon injection had indeed different sizes when quantified by PDA for the two injectors. The LD injector showed about 8-10\% smaller SMD over the first $1 \mathrm{~ms}$ ASOI than the SE injector. The effect was similar at most conditions, only slightly weaker at $80^{\circ} \mathrm{C}, 0.5$ bar.

The droplet size histograms are provided in Figure $26 \mathrm{~A}-\mathrm{B}$, as the SMD on its own requires great care when making comparisons and is known for its ambiguity where two sprays can have identical SMD but very different droplet distributions. Both injectors' histograms confirm the similarity of the sprays. Plots are mirroring each other and the 1 bar graph (Figure 24 A) shows a size peak around $8 \mu \mathrm{m}$ for both temperatures. The 0.5 bar sprays (Figure $24 \mathrm{~B}$ ) show a narrower distribution with generally smaller droplets and a peak at $6 \mu \mathrm{m}$. The $20^{\circ} \mathrm{C}$ sprays had a stronger skewness to the right. The distribution of the $80^{\circ} \mathrm{C}$ sprays is narrower and largely lacks droplets exceeding $\sim 22 \mu \mathrm{m}$ in diameter. At $20^{\circ} \mathrm{C}$, droplets up to $\sim 30$ $\mu \mathrm{m}$, were clearly present in the histograms and resulted in a larger overall SMD.
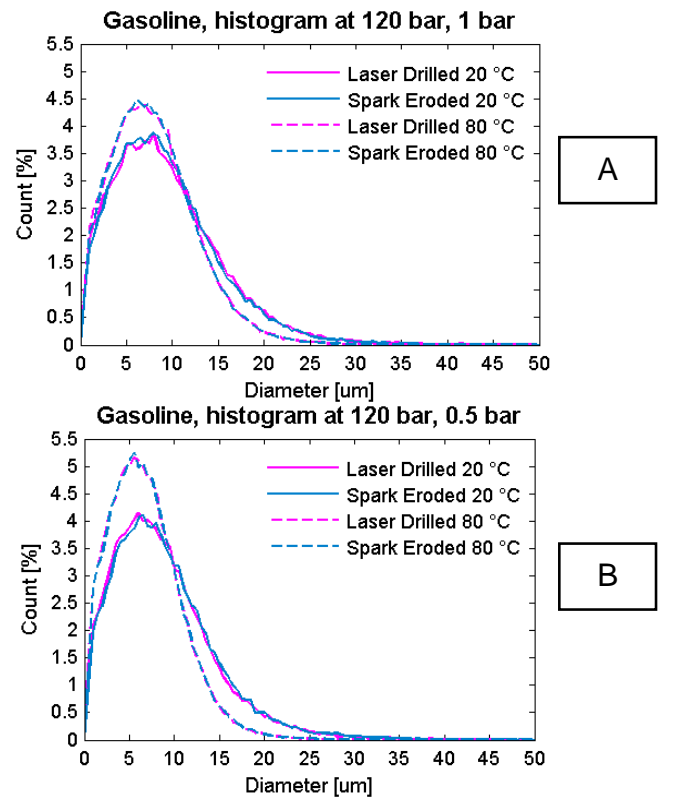

Figure 26. Histogram of droplet size for measurements of gasoline sprays at 1 bar (A) and 0.5 bar (B) back pressure. 


\section{Alcohols in LD and SE Nozzle}

The overall SMD of the fuels, averaged over all measurement positions through the spray, as well as in time, are presented in the form of bar graphs in Figure 27 A-D with the standard deviation included as error bars. Figure 13 (shown earlier) corresponds to butanol at $80^{\circ} \mathrm{C}, 0.5$ bar with the SE injector and can be useful for the reader as further reference in this section and for comparison with Figure 24.

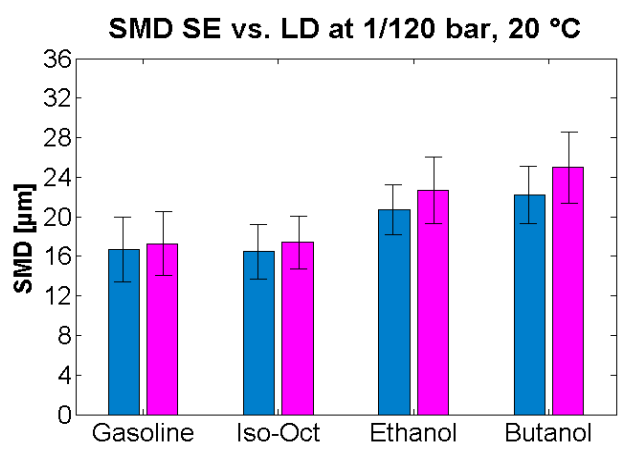

\section{A}

Spark Eroded Laser Drilled

SMD SE vs. LD at $0.5 / 120 \mathrm{bar}, 20^{\circ} \mathrm{C}$

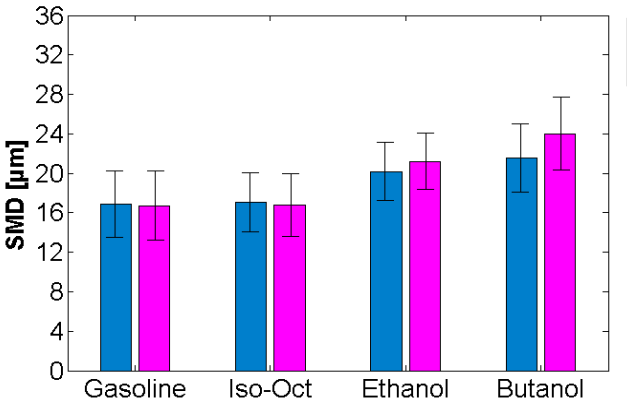

\section{$\mathrm{B}$}

Spark Eroded Laser Drilled

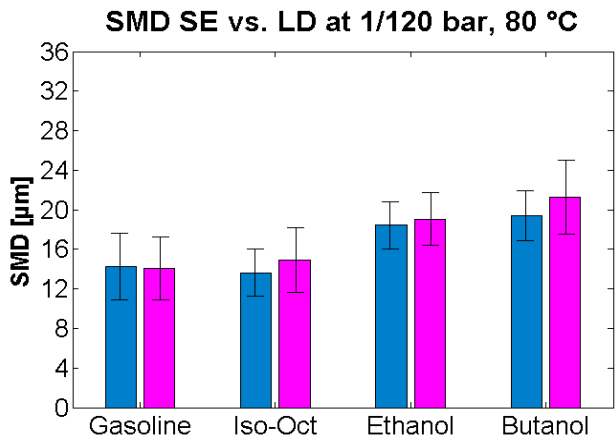

SMD SE vs. LD at $0.5 / 120 \mathrm{bar}, 80^{\circ} \mathrm{C}$

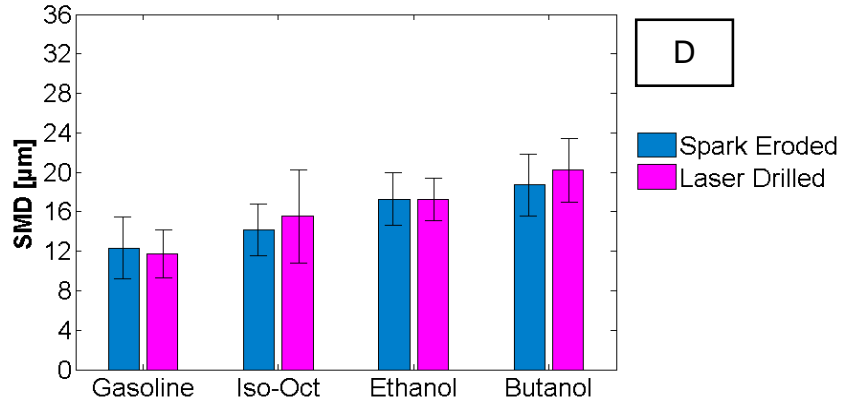

Figure 27. SMD of SE and LD injectors (overall).
SMD SE vs. LD $0-1.0 \mathrm{~ms}$ at $1 / 120$ bar, $20^{\circ} \mathrm{C}$

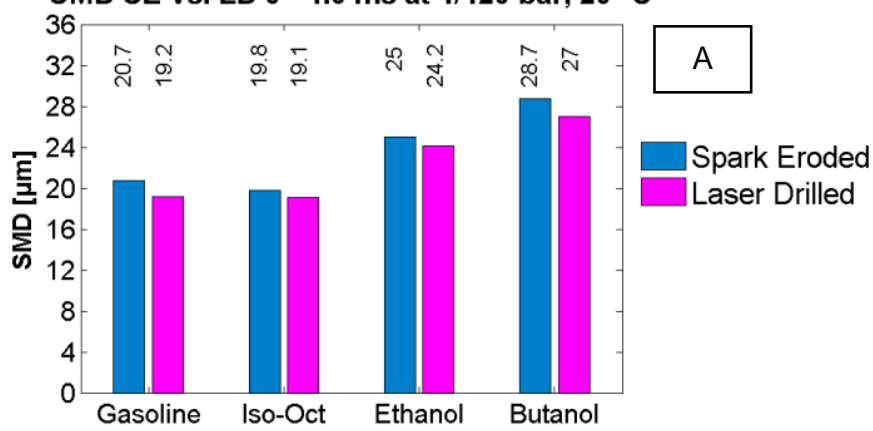

SMD SE vs. LD $0-1.0 \mathrm{~ms}$ at $0.5 / 120$ bar, $20^{\circ} \mathrm{C}$

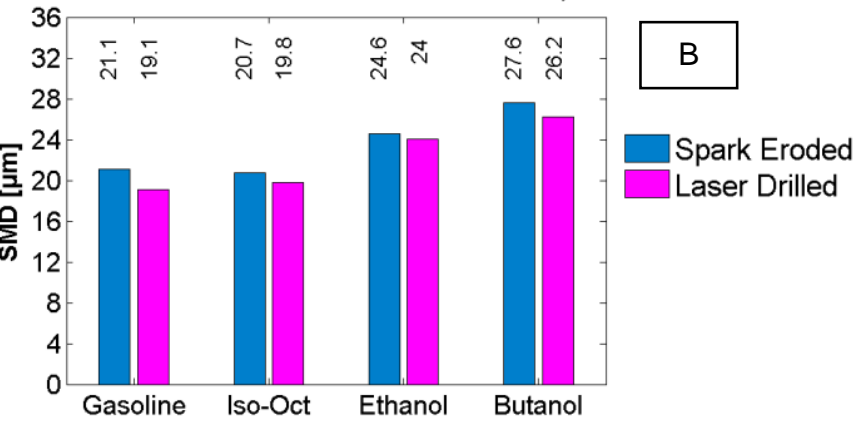

SMD SE vS. LD $0-1.0 \mathrm{~ms}$ at $1 / 120$ bar, $80^{\circ} \mathrm{C}$

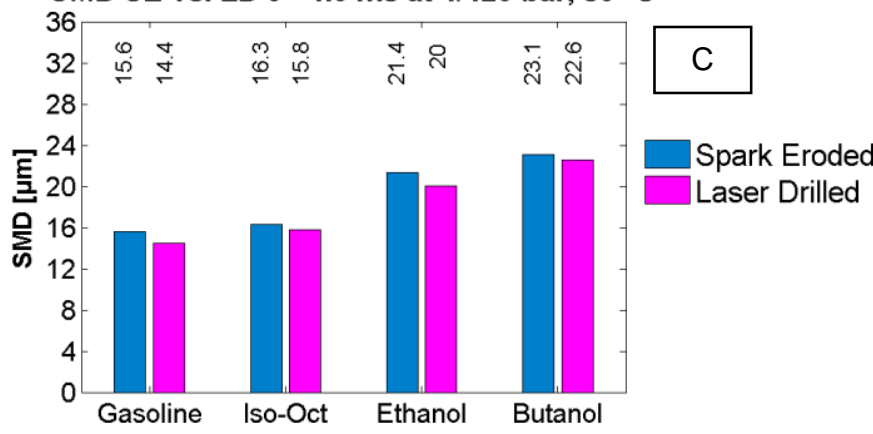

SMD SE vs. LD $0-1.0 \mathrm{~ms}$ at $\mathbf{0 . 5} / 120 \mathrm{bar}, 80^{\circ} \mathrm{C}$

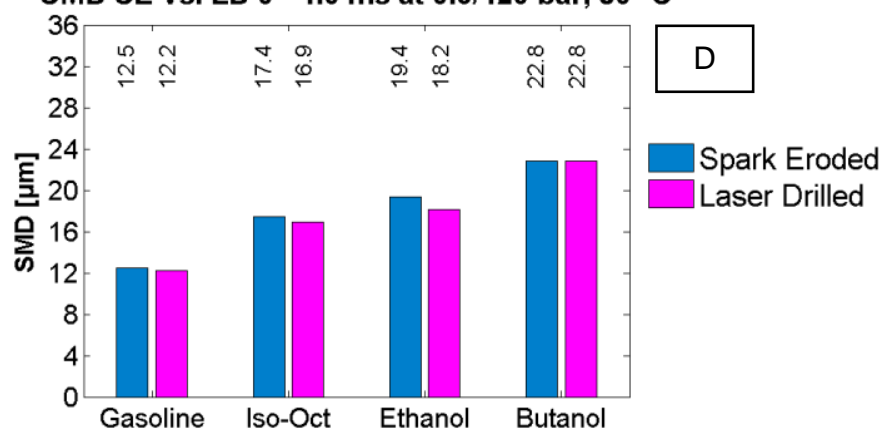

Figure 28. SMD of SE and LD injectors (1 ms ASOI).

Figure 27 shows that the droplet size generally increased compared to gasoline when injecting ethanol or butanol. Isooctane, included as a single component research surrogate for gasoline, returned droplets similar to gasoline's with the 
exception of the $80^{\circ} \mathrm{C}, 0.5$ bar condition where gasoline was strongly flash boiling in comparison to iso-octane with its high boiling point.

Despite the LD injector showing lower sensitivity to fuel properties in terms of spray geometry, the same cannot be concluded from the droplet sizing. Here, the LD injector returned larger droplets when using ethanol or butanol. Specifically for ethanol, the SMD with the LD nozzle, when compared to the SE nozzle, increased at $20^{\circ} \mathrm{C}$ by $\sim 10 \%$ and by $\sim 5 \%$, at 1 bar and 0.5 bar, respectively (Figure $27 \mathrm{~A}$ and $\mathrm{B})$. The difference was not as large at $80{ }^{\circ} \mathrm{C}$ with only $\sim 4 \%$ larger droplets at 1 bar (Figure $27 \mathrm{C}$ ) and very similar droplet size at the 0.5 bar (Figure $27 \mathrm{D}$ ).

The SMD trend was similar with butanol, where $20^{\circ} \mathrm{C}$ LD sprays returned droplets larger by 13-11\% than the SE ones. At $80{ }^{\circ} \mathrm{C}$, the LD sprays' SMD was greater by $\sim 10 \%$ and $8 \%$ for 1 bar and 0.5 bar, respectively, than that of the SE nozzle.

However, it needs to be pointed out that, as with gasoline fuelling discussed earlier that showed $8-10 \%$ reduction, the LD injector also produced smaller droplets during the early part of injection than the SE injector with both alcohols and with isooctane. For those fuels, the reduction in early SMD with the LD injector was typically in the range 5-7\% depending on conditions; butanol showed the smallest differences at $80^{\circ} \mathrm{C}$. Figure 28 summarizes this effect for all fuels over the first $1 \mathrm{~ms}$ ASOI.

\section{Summary/Conclusions}

The current investigation focused on characterizing differences in spray formation and droplet sizes from two multi-hole injectors which were declared 'like-for-like' replacements. The original injector had its nozzle holes manufactured using standard spark erosion and the replacement one was manufactured by latest Laser-drilled technology. Emphasis was placed on the effect of fuel type as well by using regular RON95 gasoline and comparing it to the alternative fuels ethanol and butanol. The conditions tested were $20^{\circ} \mathrm{C}$ and 80 ${ }^{\circ} \mathrm{C}$ injector temperatures (i.e. cold and warm engine head conditions), as well as 0.5 bar and 1 bar back pressure (i.e. high and part load engine conditions relevant to intake stroke 'homogeneous' injection strategies). Injection pressure was fixed at 120 bar.

- Both injectors had stepped holes geometries with the LD injector showing larger holes under the microscope, of the order $10-15 \%$ in diameter. However, mass flow tests quantified only about $10 \%$ increased flow rate for the LD injector, highlighting potential differences in cavitation patterns inside the nozzles for the two injectors due to further differences in the design of the injector's internals.

- Visual analysis of the spray images, spray angle analysis and phase Doppler droplet sizing clearly indicated wider sprays for the LD injector (i.e. better fuel dispersion).

- Spray shapes differed significantly between fuels, more so at hot than at cold conditions. At $80^{\circ} \mathrm{C}$ injector temperature, gasoline sprays exhibited flash boiling and collapsed more than ethanol's. No clear spray collapse was visible for butanol at the same conditions.
- The alcohols showed a distinct delay in appearing at the nozzle in comparison to gasoline with both injectors. However, in general, fuel spray appeared earlier with the LD injector, especially for the alcohols at $20^{\circ} \mathrm{C}$ when compared to the SE injector.

- Differences in spray geometry between fuels were generally smaller with the LD injector than with the SE one, as demonstrated by spray tip penetration and angle data.

- With both injectors flash boiling fuels featured a strong spray angle increase at $5 \mathrm{~mm}$ past the nozzle, whilst subsequent spray collapse returned reduced angles $25 \mathrm{~mm}$ downstream the nozzle tip.

- In general the LD injector, despite its faster early penetration achieved lower vertical penetration than the SE injector past $0.9 \mathrm{~ms}$ ASOI for most conditions. This was associated with its simultaneous wider dispersion that could be beneficial in terms of mixture preparation and reduced piston wall wetting, which in turn could reduce emissions.

- However, at low-load warm engine conditions ( 0.5 bar back pressure, $80^{\circ} \mathrm{C}$ injector body temperature), the LD injector showed greater spray collapse and longer vertical penetration than the SE injector due to concentrated axial momentum from more severe plume merging. This can work opposite to the SE injector and to other conditions in terms of piston wall impingement and associated emissions. However, even for heavy flash boiling, there is a clear margin for improvement with the LD injector in comparison to the SE at fixed air-to-fuel ratio requirements for both injectors, since the higher flow rate of the LD injector would require lower injection pulse duration which in turn would lead to a reduction in penetration.

- Temperature increase led to reduced droplet sizes with both injectors for all fuels.

- The effect of back pressure reduction was also a clear reduction in droplet sizes, especially at $80^{\circ} \mathrm{C}$. At $20^{\circ} \mathrm{C}, 0.5$ bar, the alcohol fuels featured greater droplet size reduction with both injectors.

- Gasoline sprays with the SE and LD injectors showed similar droplet size histograms. The LD injector exhibited marginally smaller SMD than the SE with 0.5 bar back pressure at both $20^{\circ} \mathrm{C}$ and $80^{\circ} \mathrm{C}$ injector temperatures. Similarly marginal differences were observed between the two injectors at 1 bar, with the LD nozzle exhibiting sub 1 $\mu \mathrm{m}$ smaller droplets at $80^{\circ}$ and larger at $20^{\circ} \mathrm{C}$.

- The LD injector returned larger droplets with ethanol and butanol than the SE injector, with the difference reduced at test conditions that approached the fuel's boiling point.

- The LD injector exhibited clearly smaller clustered droplets at the initial tip of the spray for all fuel types. This was observed by imaging and then quantified by droplet sizing to be in the region of $5-10 \%$, depending on test conditions.

- Needle bounce was visible for the LD injector at closing time and this led to secondary injection effects. The effect was more evident with the low viscosity fuels at hot conditions. Contribution of this to mean droplet sizes was examined but no major quantitative effect was identified.

- Injectors, even though specified as 'like-for-like' replacements by manufacturers, still need to be analysed regarding their actual performance by engine developers, especially if modifications to the nozzle are present, as differences in flow rates, spray geometry and droplet sizes may be manifested. 


\section{References}

1. Whitaker, P., Kapus, P., Ogris, M. and Hollerer, P., 2011, "Measures to Reduce Particulate Emissions from Gasoline DI engines", SAE Paper 2011-01-1219.

2. Cascone, R., 2008, "Biobutanol a Replacement for Bioethanol?", Chemical Engineering Progress, Vol. 104, Society for Biological Engineering, Special Section Biofuels, pp. 4-9.

3. Callies, G., Willert, M, and Osswald, K., 2007, "Method and Device for Laser Drilling in a Process Gas Atmosphere", Patent No US 7,301,121 B2.

4. Macián, V., Bermudez, V., Payri, R., and Gimeno, J. "New technique for determination of internal geometry of a Diesel nozzle with the use of silicone methodology", Experimental Techniques, Vol. 27, pp. 39-43, 2003.

5. Butcher, A. J., Aleiferis, P.G. and Richardson, D., "Development of a Real-Size Optical Injector Nozzle for Studies of Cavitation, Spray Formation and Flash Boiling at Conditions Relevant to Direct-Injection Spark-Ignition Engines", International Journal of Engine Research, Vol. 14, pp. 557-577, 2013.

6. Reitz, R.D. and Bracco, F.V., 1982, "Mechanisms of Atomization of a Liquid Jet", Physics of Fluids, Vol. 25, pp. 1730-1742.

7. Serras-Pereira, J., Aleiferis, P.G, Richardson, D. and Wallace, S., 2008, "Characteristics of Ethanol, Butanol, iso-Octane and Gasoline Sprays and Combustion from a Multi-Hole Injector in a DISI Engine", SAE International Journal of Fuels and Lubricants, Vol. 1, pp. 893-909, Paper 2008-01-1591.

8. Aleiferis, P.G. and van Romunde, Z.R, 2013. "An Analysis of Spray Development with iso-Octane, n-Pentane, Gasoline, Ethanol and n-Butanol from a Multi-Hole Injector under Hot Fuel Conditions", Fuel, Vol. 105, pp. 143-168.

9. Aleiferis, P.G., Serras-Pereira, J., van Romunde, Z., Caine, J. and Wirth, M., 2010, "Mechanisms of Spray Formation and Combustion from a Multi-Hole Injector with E85 and Gasoline", Combustion and Flame, Vol. 157, pp. 735-756.

10. Poling, B.E., Prausnitz, J.M., O’Connel, J.P., 2001. "The Properties of Gases and Liquids", 5th Edition, McGrawHill.

11. Owen, K., Coley, T. 1995. "Automotive Fuels Reference Book". Society of Automotive Engineers.

12. Yaws, C.L. 2003. 'Yaws' Handbook of Thermodynamic and Physical Properties of Chemical Compounds" Knovel (accessed 03/2011). http://www.knovel.com.

13. Beeckmann, J., Rohl, O., Peters, N. 2009. „Numerical and experimental investigation of laminar burning velocities of iso-Octane, ethanol and n-Butanol". SAE Paper 2009-012784

14. Beekmann, J., Krause, S., Peters, N. 2010. „Effect of Ethanol and n-Butanol on Standard Gasoline Regarding Laminar Burning Velocities". SAE Paper 2010-01-1452.

15. Gupta, R.B., Demirbas, A. 2010. „Gasoline, Diesel and Ethanol Biofuels from Grasses and Plants". Cambridge University Press.

\section{Contact Information}

Dr. Pavlos Aleiferis, Department of Mechanical Engineering, University College London, Torrington Place, London WC1E 7JE, United Kingdom, E-mail: p.aleiferis@ucl.ac.uk.

\section{Acknowledgements}

MAHLE Powertrain are gratefully acknowledged for financial and technical support. Rob Robinson at Jaguar Land Rover is also gratefully acknowledged for providing the injectors for this work.

\section{Definitions/Abbreviations}

DISI

Direct Injection Spark Ignition

ASOI

After Start of Injection

B100

Butanol

E100

Ethanol

FUP

Fuel Pressure

FUT

Fuel Temperature

LD

Laser Drilled

MH7

7 hole multi-hole injector

PDA

Phase Doppler Anemometry

PLC

Programmable Logic Controller

SE

Spark Eroded

SMD

Sauter Mean Diameter 


\section{Appendix}
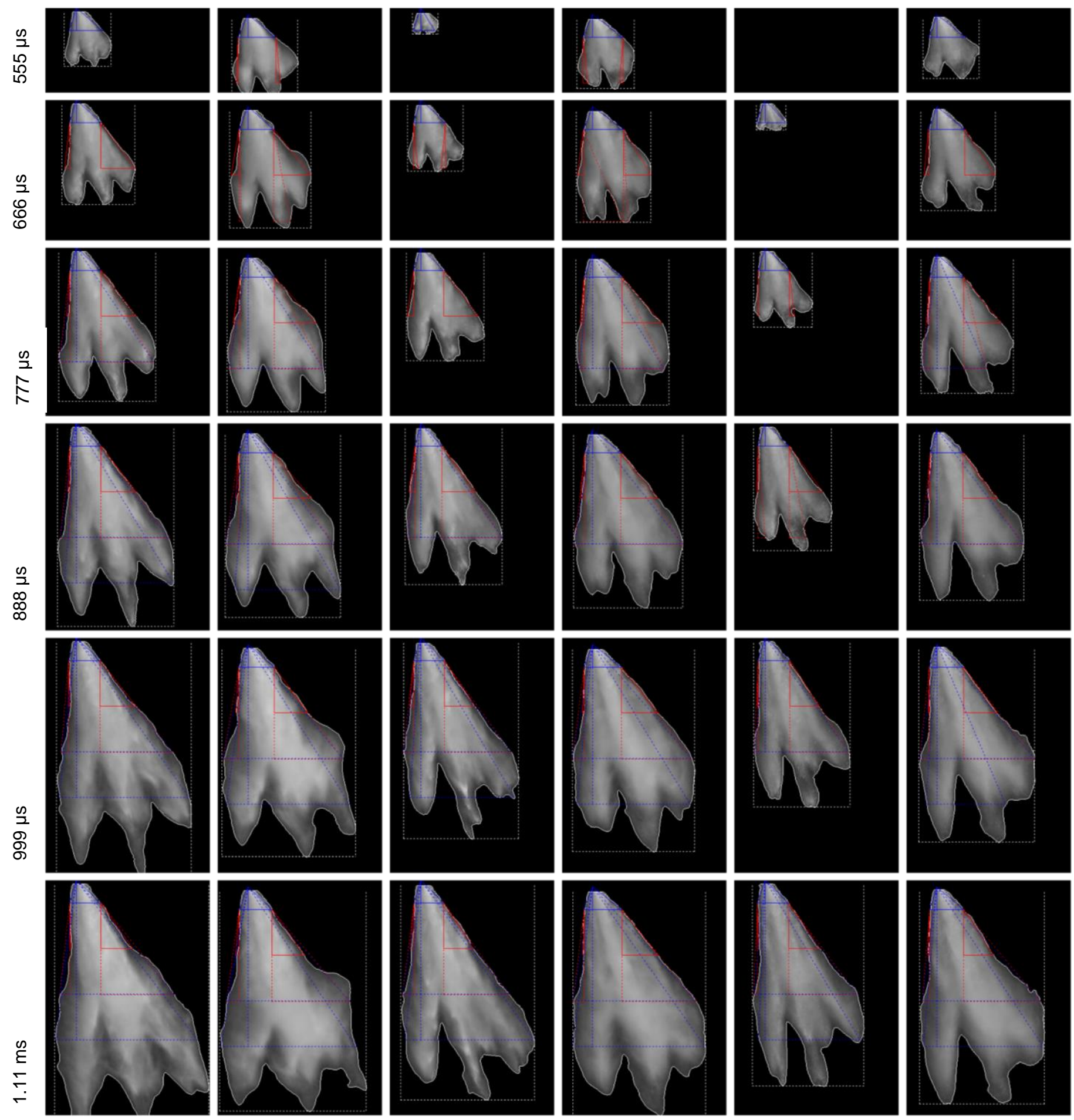

Gasoline SE Gasoline LD

Ethanol SE

Ethanol LD

Butanol SE

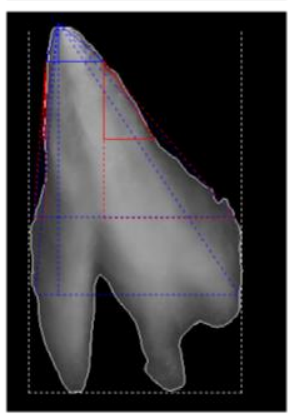

Butanol LD

Figure 29. Spray imaging at $20^{\circ} \mathrm{C}$ injector temperature, 1 bar air pressure. 

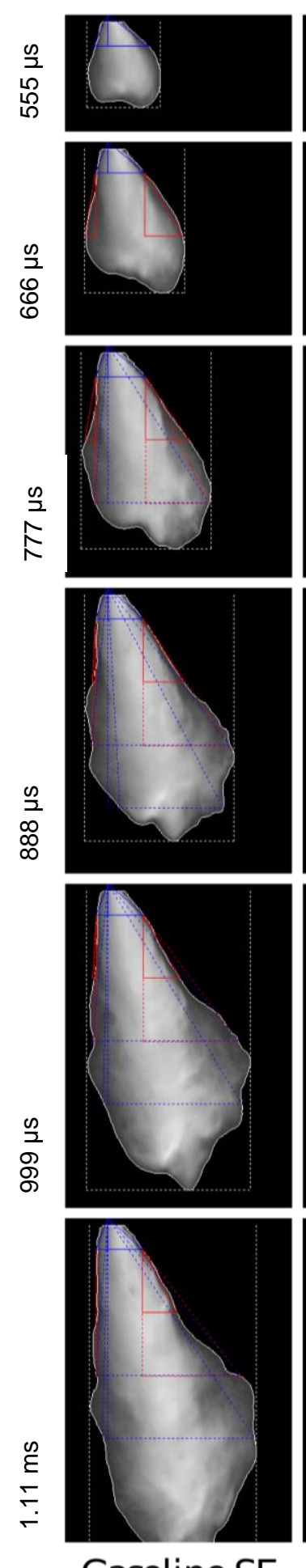

Gasoline SE
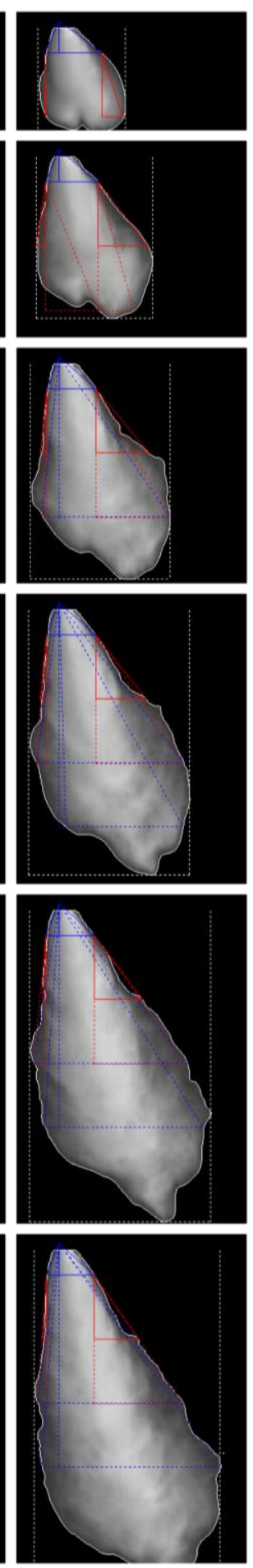

Gasoline LD
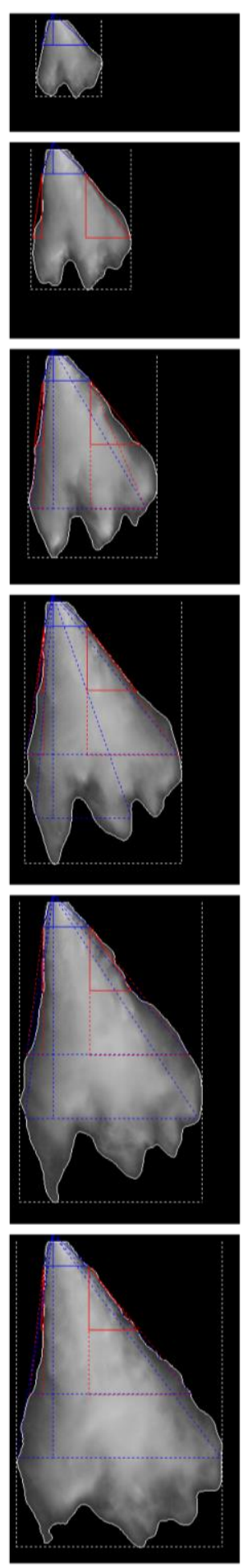

Ethanol SE
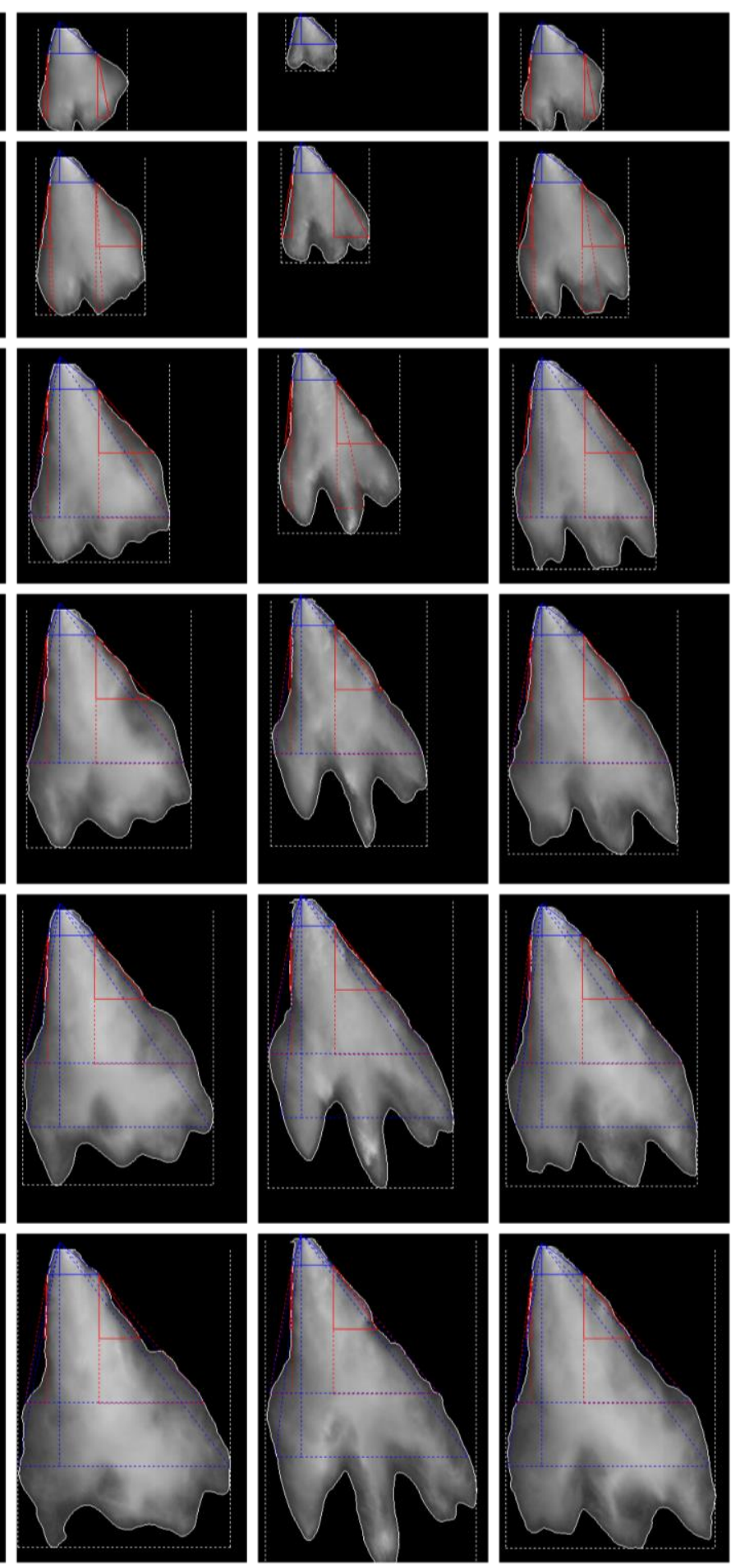

Butanol SE
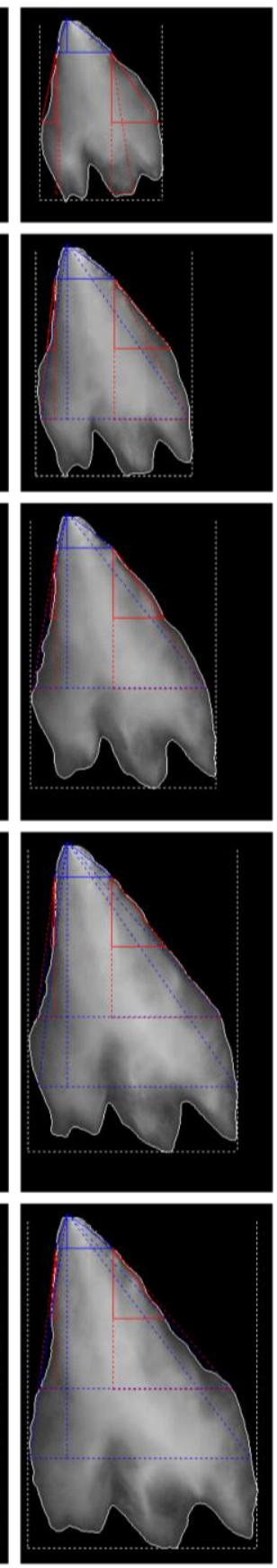

Ethanol LD

Butanol LD

Figure 30 . Spray imaging at $80{ }^{\circ} \mathrm{C}$ injector temperature, 1 bar air pressure. 